\title{
IMMUNOSUPPRESSIVE STRATEGIES THAT ARE MEDIATED BY TUMOR CELLS
}

\author{
Gabriel A. Rabinovich ${ }^{1,3}$, Dmitry Gabrilovich ${ }^{2}$, and Eduardo M. Sotomayor ${ }^{2}$ \\ 1'Division of Immunogenetics, Hospital de Clínicas “José de San Martín”, University of Buenos Aires, \\ Buenos Aires, Argentina \\ ${ }^{2}$ Department of Interdisciplinary Oncology, H. Lee Moffitt Cancer Center \& Research Institute at the \\ University of South Florida, Tampa, FL 33612
}

\section{Abstract}

Despite major advances toward an improved understanding of the mechanisms leading to tumor immunity, the successful translation of mechanistic insights into effective tumor immunotherapy is hindered by a number of immunological obstacles. These include the ability of tumors to foster a tolerant microenvironment and the activation of a plethora of immunosuppressive mechanisms, which may act in concert to counteract effective immune responses. Here we will discuss different strategies employed by tumors to thwart immune responses, including tumor-induced impairment of antigen presentation, activation of negative costimulatory signals and elaboration of immunosuppressive and pro-apopoptic factors. In addition, we will underscore the influence of regulatory cell populations that may contribute to this immunosuppressive network including regulatory T cells, NKT cells and distinct subsets of immature and mature dendritic cells. The current wealth of preclinical information promises a future scenario in which the synchronized blockade of immunosuppressive mechanisms and the removal of inhibitory signals might be effective in combination with other conventional strategies to overcome immunological tolerance and promote tumor regression.

\section{Keywords}

cancer; immunosuppression; immunoediting; tumor-immune escape; dendritic cells; regulatory T cells; immunotherapy

\section{Cancer Immunoediting: A Unifying Perspective of Cancer Immunosurveillance and Tumor-Immune Escape}

\begin{abstract}
During the past few years we have witnessed a breakthrough in the understanding of the cellular and molecular mechanisms of immune cell activation and homeostasis. Such extensive progress in defining the cellular and molecular networks that regulate the immune response in the tumor microenvironment has renewed our enthusiasm in the potential power of cancer immunotherapy. However, the successful translation of novel mechanistic insights into effective tumor immunotherapy is hindered by a number of obstacles including the ability of tumor cells to generate a tolerant microenvironment, the activation of negative regulatory checkpoints in the tumor microenvironment and the secretion of immunosuppressive cytokines
\end{abstract}

\footnotetext{
${ }^{3}$ Address correspondence to: Dr. Gabriel A. Rabinovich, División Inmunogenética. Hospital de Clínicas “José de San Martín”. Facultad de Medicina. Universidad de Buenos Aires. Av. Córdoba 2351. $3^{\text {er }}$ Piso. (C1120) Ciudad de Buenos Aires. Argentina. TE: +54-11-5950-8755. Fax: +54-11-5950-8758. gabyrabi@ ciudad.com.ar.
} 
and soluble inhibitory factors $(1,2)$. These immunosuppressive strategies can either be "preexisting", arise through outgrowth of escape mutants, or take place during tumor-sculpting actions by the immune system (3).

The "cancer immunoediting" hypothesis, recently put forward by Schreiber and colleagues (3) has integrated the different mechanisms of tumor-immune escape with the "immunosurveillance theory" originally conceived in the early $20^{\text {th }}$ by Paul Ehrlich and postulated in the mid-20 th by Sir Marcfarlane Burnet and Lewis Thomas. The renaissance of tumor immunosurveillance in the new concept of "immunoediting" holds the idea that the immune system not only protects the host against tumor development, but can also promote tumor growth by selecting for tumor escape variants with reduced immunogenicity (3). Using gene targeting experiments, the authors showed that the process of cancer immunoediting is comprised of three phases (4). The first phase called "Elimination" essentially refers to cancer immunosurveillance, in which cells of the innate and adaptive immune systems (including NK, $\alpha \beta$ and $\gamma \delta$ T cells) and immunoregulatory molecules (including IFN- $\gamma$, IL-12, perforin and TRAIL) recognize and destroy developing tumors, thus protecting the host against cancer. The second phase is "Equilibrium", similar to the concept of tumor dormancy, which is a protracted period in which the tumor and immune system enter into a dynamic equilibrium. The third phase is "Escape", where tumor variants that emerge by an immune selection process from the equilibrium phase develop into clinically apparent tumors that grow in an immunocompetent host $(3,4)$. Underscoring a new optimism that an enhanced understanding of the interactions between tumors and the immune system will lead to the development of novel cancer immunotherapy strategies, we will summarize here recent findings on the mechanisms leading to immune tolerance at the tumor microenvironment and the immunosuppressive strategies used by tumors to evade immune responses.

\section{Tolerance to Tumor Antigens Induced by Malignant Cells}

A fundamental change in our view of tumor immunology occurred in the early 90 's following the surprising observations that most of the antigens expressed by tumor cells were not necessarily neo-antigens uniquely present in cancer cells, but rather tissue-differentiation antigens also expressed in normal cells $(5,6)$. These unexpected findings led to the hypothesis that probably the greatest obstacle for harnessing the immune system against tumors was the immune system itself, and more specifically, its complex mechanisms for establishing T-cell tolerance against self- and by extension, to tumor antigens, most of them also considered as "self" (7). Experimental evidence supporting the above hypothesis was provided by the Bogen's and Levitsky's groups who independently demonstrated that antigen-specific CD4 ${ }^{+}$ $\mathrm{T}$-cells were indeed rendered tolerant during tumor growth in vivo $(8,9)$. Following the initial report of this phenomenon termed "tumor-induced anergy", several studies showed that this state of T-cell unresponsiveness also occurs during the growth of hematologic or solid tumors expressing model or true tumor antigens (10-12), during the progression of spontaneously arising tumors (13) and more importantly during the progression of human cancers $(14,15)$. Therefore, there is now an undisputed realization that the induction of tolerance to tumor antigens, through mechanisms akin to those that regulate responses to self-antigens, represents an important immunosuppresive strategy by which tumor cells might escape T-cell-mediated anti-tumor responses. This different view of tumor immunity has also raised the bar for cancer immunotherapy, since the barrier imposed by immune tolerance must be broken in order for the immune system to effectively recognize and eliminate tumors expressing mainly "self" (16) (Fig. 1). Given the importance of this homeostatic regulatory mechanism, in the following sections we will discuss the cellular and molecular bases by which tolerance towards tumor antigens is established and maintained and what steps can be taken to overcome, in a controllable fashion, this remarkable obstacle for cancer immunotherapy. 


\subsection{Tumor-induced antigen-specific CD4+ ${ }^{+}$-cell tolerance}

Most of our current knowledge of tumor antigen recognition by CD4+ $4^{+}$-cells, was initially gathered from the in vivo analysis of the fate and function of T-cell receptor (TCR) transgenic $\mathrm{T}$ cells specific for model antigens expressed by genetically engineered tumors (9). In this system, the adoptive transfer of naïve transgenic $\mathrm{CD}^{+} \mathrm{T}$-cells specific for hemaglutinin influenza (HA) into mice with established A20 B-cell lymphoma expressing HA as model tumor antigen (A20HA), resulted in a transient expansion of clonotype-positive T-cells as well as phenotypic changes associated with antigen recognition. However, these cells had a diminished response to cognate peptide in vitro and were unable to be primed following vaccination with a potent immunogen in vivo. Therefore, tumor antigen-recognition by antigenspecific T-cells occurs in vivo, but anergy rather than T-cell priming was the default outcome of such an encounter in tumor-bearing hosts. These sobering observations on the fate and function of naïve antigen-specific T-cells were recently extended to memory $\mathrm{CD} 4^{+} \mathrm{T}$-cells with the demonstration that antigen-experienced T-cells are also rendered unresponsive during tumor progression (17). In addition, the induction of this state of anergy is not only a characteristic of hematologic tumors, given the findings that growth of solid malignancies is also accompanied by a similar $\mathrm{CD} 4^{+} \mathrm{T}$-cell functional outcome in vivo $(10,18)$. Interestingly, in all these experimental models, the induction of $\mathrm{CD}^{+} \mathrm{T}$-cell anergy coincided with the loss of therapeutic vaccine efficacy, indicating that tolerance to tumor antigens is in indeed a significant barrier to therapeutic vaccination. The fact that such a barrier also exists in humans was recently confirmed in patients with cancer, in whom $\mathrm{CD}^{+} \mathrm{T}$-cells were also found to be functionally unresponsive $(14,15)$.

Although the above studies unveiled the ability of tumors to induce CD4 $4^{+} \mathrm{T}$-cell anergy in vivo, the mechanisms of tolerance induction, the composition of the tolerized population and their potential fate were not elucidated until more recently. Given the profound impairment in the function of tumor-antigen specific T-cells -as determined by their blunted proliferation and cytokine production in response to cognate antigen- it was initially thought that the whole tumor-specific $\mathrm{CD}^{+}{ }^{+} \mathrm{T}$-cell population was rendered anergic by the growing malignancy. However, a more detailed analysis of this T-cell population by Zhou and colleagues, surprisingly revealed that only a minority of tumor-specific T-cells are functionally anergic, while the large majority of the total pool of antigen-specific T-cells remained naïve or "ignorant "of the tumor (19). Interestingly, in this study a proportion of the responding cells differentiated into regulatory T-cells capable of suppressing the response of both naïve as well as effector cells in vitro. These results provided a more complex picture of tumor-antigen recognition by $\mathrm{CD}^{+} \mathrm{T}$-cells, i.e., their in vivo interaction with tumor cells led to a heterogeneous T-cell population composed of antigen-experienced T-cells (among them anergic T-cells), naïve Tcells as well as the emergence of tumor-specific regulatory T-cells displaying immunosuppressive properties. How these distinct cell populations are induced and what cellular and/or molecular mechanism(s) influence the final composition of these mixture of tumor-specific T-cells remains however to be elucidated.

\subsection{Tumor-induced antigen-specific $\mathrm{CD} 8^{+} \mathrm{T}$-cell tolerance}

Anergy induction by tumors is not limited to the $\mathrm{CD} 4^{+} \mathrm{T}$-cell compartment, since tumor progression in experimental models and in humans has been shown to be associated with functional impairment in antigen-specific $\mathrm{CD} 8^{+} \mathrm{T}$-cells. However, there is still an intense debate as to how to define tolerance in the $\mathrm{CD}^{+} \mathrm{T}$-cell compartment. Early studies of antigenspecific CD8 ${ }^{+} \mathrm{T}$-cell responses equated peripheral tolerance with either "ignorance" or clonal deletion although more recent evidence has suggested that this may be only partly accurate. It was initially considered that the lack of cytotoxic T lymphocyte (CTL) efficacy in controlling tumor growth just reflected "tumor ignorance", since antigen-specific cytotoxic responses, proliferation and cytokine production could be measured upon in vitro re-stimulation or 
secondary immunization against tumor antigen $(20,21)$. Still other studies have indicated that $\mathrm{CD}^{+} \mathrm{T}$-cells are, indeed, rendered tolerant to tumor antigens $(11,12,22,23)$. For instance, Lyman et al. have shown that antigen-specific $\mathrm{CD} 8^{+} \mathrm{T}$-cells did not develop an effector function in the face of an increasing tumor burden and tumor antigen availability (23). In another study, $\mathrm{CD} 8^{+} \mathrm{T}$-cells displaying an antigen-experienced phenotype were detected in regional draining lymph nodes or in non-lymphoid sites where the antigen was present. However, these $\mathrm{CD} 8^{+} \mathrm{T}$-cells were typically deficient in one or more effector functions, a phenomenon termed "split anergy" (24,25). More recently, Overwijk et al. developed a transgenic mice (Pmel-1 mice) that have a transgene encoding a TCR specific for the self/tumor antigen gp100 (12). Reminiscent of the findings observed in transgenic T-cell specific for "model tumor antigens", Pmel-1 antigen-specific CD8 ${ }^{+}$T-cells were also found to be tolerant and as such unable to innately confer protection against B16 melanoma expressing a "true" tumor antigen (12). Studies in melanoma patients have confirmed these experimental observations, since $\mathrm{CD} 8^{+} \mathrm{T}$-cells specific for the tumor associated antigens MART-1 or tyrosinase were also shown to be tolerant, as determined by their poor cytolytic and proliferative capacities upon in vitro stimulation, despite phenotypic evidence of previous cognate antigen encounter and normal responses to unrelated antigens (14). Therefore, CD8 ${ }^{+}$ $\mathrm{T}$-cell tolerance to tumor antigens likely exists, although the mechanisms and functional consequences of this effect still remain to be fully elucidated.

\subsection{Cellular and molecular mechanisms involved in the induction of tolerance to tumor antigens}

An important question that rapidly emerged after the initial demonstration of tumor-induced antigen-specific T-cell tolerance was whether this state of unresponsiveness was induced by tumors themselves or by immune cells, specifically bone marrow-derived antigen-presenting cells (APCs). Utilizing parent-into-F1 bone marrow chimeras we unambiguously demonstrated that tumor antigen processing and presentation by APCs (not direct presentation by tumor cells) was the dominant mechanism underlying the development of tumor antigen-specific $\mathrm{CD} 4^{+} \mathrm{T}$ cell tolerance (26). This critical role of APCs was operative not only in mice challenged with tumor cells that have an intrinsic antigen-presentation capabilities (B-cell lymphoma), but also in mice challenged with solid tumors that are ill-equipped to present cognate antigen to $\mathrm{CD}^{+} \mathrm{T}$-cells (10). These studies demonstrated therefore that the intrinsic APC capacity of tumor cells has little influence over T-cell priming versus tolerance, a critical decision that is regulated at the level of BM-derived APCs.

Dendritic cells (DCs), macrophages and B-cells are all BM-derived cells that express major histocompatibility complex (MHC) as well as co-stimulatory molecules and, as such, can potentially present tumor antigen to antigen-specific T-cells in vivo. Although it is plausible that under particular conditions each population might induce divergent T-cell outcomes (27, 28), several lines of evidence have pointed to DCs in particular, as playing a critical role in the decision leading to T-cell tolerance versus T-cell priming in vivo $(27,29,30)$. Such a decision, it is now known, is greatly influenced by the environmental context in which the antigen is encountered by DCs. As will be discussed in detail in a later section, while antigen encounter by DCs in an inflammatory context trigger their maturation to a phenotype capable of generating strong immune responses, antigen capture by DCs in a non-inflammatory environment would fail to elicit productive T-cell responses leading instead to the development of T-cell tolerance (27). The latter scenario -absence of inflammatory mediators- illustrates how DCs would normally encounter tumor antigens in vivo, an event that unfortunately is conducive to T-cell unresponsiveness rather than T-cell priming (30). Adding complexity to this sobering outcome, as tumor progresses, its microenvironment not only fails to provide inflammatory signals needed for efficient DC activation, but it would impose additional immunosuppressive mechanisms such as IL-10 (31) and vascular endothelial growth factor 
(VEGF) (32) that will further impact negatively upon DC's maturation and/or function. Therefore, it is in this non-inflammatory and even "hostile" environment in which DCs would likely encounter tumor antigens in vivo, acquire "tolerogenic" properties and subsequently induce and maintain T-cell tolerance to tumor antigens. Although the signaling and molecular mechanisms by which the tumor microenvironment might induce tolerogenic DCs have not been fully elucidated, emerging evidence points to Stat 3 signaling in tumor cells as playing a role in this process $(33,34)$. The contribution of different subsets of DC to the immunosuppressive network of the tumor microenvironment will be discussed in detail in the last section of this review.

In lieu of the demonstrated ability of APCs, and in particular DCs, to induce both T-cell tolerance as well as T-cell priming, it was proposed that probably a delicate balance between activating and inhibitory pathways in these cells may play a role in determining such divergent T-cell outcomes. Among those inhibitory signaling pathways, Stat 3 has been particularly shown to be a critical regulator of inflammation in several in vivo systems and its absence has been associated with the occurrence of autoimmune inflammation in vivo (35). As such, we evaluated whether manipulation of this signaling pathway in APCs could influence the functional outcome of antigen-specific $\mathrm{CD}^{+}{ }^{+} \mathrm{T}$-cells. Disruption of Stat 3 signaling either pharmacologically (through tyrosine kinase inhibitor, AG-490) or by genetic manipulation (LysMcre/Stat $3^{\text {flox/- }}$ mutant mice) resulted in enhanced priming of naïve antigen-specific $\mathrm{T}$ cells and restoration of responsiveness of anergic CD4 ${ }^{+} \mathrm{T}$-cells (34). Conversely, increased Stat 3 activity in APCs was associated with impaired CD4 ${ }^{+} \mathrm{T}$-cell responses. Furthermore, our findings that T-cell tolerance occurs in mice with an intact Stat3 signaling in APCs, but not in mice with targeted disruption of this pathway highlights a critical role for Stat 3 in the in vivo induction of T-cell tolerance (34). Similarly, in an in vivo model of tumor-induced antigenspecific T-cell tolerance, we have recently found that cross-presentation of tumor antigens by APCs in Stat $3^{-/-}$mice leads to activation rather than tolerance of antigen-specific CD4 ${ }^{+} \mathrm{T}^{-}$ cells. This preservation of T-cell function was associated with a delay in melanoma cell growth in Stat $3^{-/-}$mice as compared to control mice (Cheng et. al, unpublished observations). Stat3 signaling in APCs represents, therefore, a novel molecular target for manipulation of immune activation/immune tolerance, a central decision with profound implications for cancer immunotherapy, autoimmunity and transplantation .

As expected, Stat3 signaling seems not to be the only intracellular pathway determining the immuno-stimulatory capabilities of APCs. Recent studies have also identified SOCS1 as playing an important role in the regulation of APC's function, since inhibition of this molecule by specific siRNA resulted in breaking of tolerance towards the self-antigen Trp2 (36).

Furthermore, the demonstration that tyrosine phosphorylation of certain intracellular targets influences APC function (37), led us to evaluate the effects of the tyrosine kinase inhibitor Imatinib Mesylate -an inhibitor of $c$ - $a b l, c$-kit and PDGFR tyrosine kinases- on the APC's ability to prime rather than tolerize tumor-specific T cells (38). In vitro treatment of APCs with this drug enhanced the activation of naïve antigen-specific T-cells and restored the responsiveness of tolerant T-cells from tumor bearing hosts. More importantly, in vivo treatment with imatinib not only prevented the induction of tolerance in tumor-specific $\mathrm{CD}^{+} \mathrm{T}$-cells, preserving their responsiveness to a subsequent immunization, but also resulted in enhanced vaccine efficacy (38). Molecular studies of imatinib-treated APCs showed that among all the known molecular targets of STI-571, inhibition of $c$-kit phosphorylation seems to be the likely target in these cells. These findings demonstrate that tolerance to tumor antigens is not an insurmountable obstacle and point to $c$-kit signaling in APCs as an additional target to overcome mechanisms of T-cell tolerance in cancer. 


\subsection{Reverting T-cell tolerance to tumor antigens}

The better understanding of the cellular and molecular mechanisms involved in the induction and establishment of tolerance to tumor antigens provided the appropriate framework for the development of therapeutic strategies targeting this barrier for cancer immunotherapy. Some of these strategies such as CTLA-4 blockade in T-cells or CD40 activation of APCs have been already proven to be effective in experimental models and are currently being evaluated in cancer patients, while others are still being tested in pre-clinical models. The rationale for targeting CTLA-4, a negative regulator of T-cell activation (39) was based upon the demonstration of its role in tolerance induction in vivo (40) and the findings that treatment of tumor-bearing mice with blocking anti-CTLA-4 antibodies, before and after adoptive transfer of tumor-specific T-cells, resulted in an enhanced response to subsequent vaccination (41). These results were further confirmed in melanoma models in which the combination of a GMCSF tumor cell-based vaccination with anti-CTLA-4 antibodies was associated with strong antitumor effect and development of vitiligo as a manifestation of tissue-specific autoimmune responses, likely triggered by CTLA-4 blockade (42). Importantly, a similar pattern of induction of antitumor activity and autoimmunity was also observed in melanoma patients treated with anti-CTLA-4 antibodies and peptide vaccination (43). Seems therefore that triggering of tissue-specific autoimmunity will likely be "the price to be paid" in our efforts to break tolerogenic mechanisms and elicit stronger antitumor responses in tumor-bearing hosts. In this regard, Daniels and colleagues have recently provided one of the best evidence to date supporting the concept of inducing autoimmunity as a mean of triggering effective tumor recognition and rejection (44). They showed that intradermal injection of plasmid DNA encoding the herpes simplex virus thymidine kinase (HSVtk) gene transcriptionally controlled by the tyrosinase promoter (Tyr-HSVtk), along with Hsp70, led not only to "inflammatory killing" of normal melanocytes, but more importantly, to the generation of a CD8 ${ }^{+} \mathrm{T}$-cell dependent, antigen-specific response capable of eradicating established melanoma tumors (44). Importantly, some animals subjected to this approach developed vitiligo but no overt autoimmunity. Therefore, "intentional" but, controlled inflammatory destruction of normal cells, by breaking tolerance to self-antigens, might represent a potential strategy to overcome tolerance and generate immunity against tumors originating from specific tissues.

The demonstration of the role of APCs in the induction of tolerance to tumor antigens prompted the search for strategies that, by modulating the inflammatory status of these cells might influence the functional outcome of tumor antigen specific T-cells. Among those strategies, treatment of tumor-bearing animals with activating anti-CD40 antibodies was shown to convert a tolerogenic event into a priming event of antigen-specific $\mathrm{CD}^{+} \mathrm{T}$-cells leading to enhanced response to vaccination (45). Similarly, in vivo triggering of CD40 overcame peptide-induced peripheral CTL tolerance and markedly increased the efficacy of peptide-based anti-tumor vaccines (46). Currently, strategies involving manipulation of the CD40/CD40Ligand pathway are under clinical evaluation in a variety of human cancers. Another strategy, although still in pre-clinical testing, is the therapeutic manipulation of the co-stimulatory receptor OX40, an approach that has been already shown to break tolerance (47) and to enhance the responses to neu vaccination in breast cancer models (48). More recently, we have also demonstrated that the tyrosine kinase inhibitor Imatinib Mesylate can prevent the development of tumor-induced $\mathrm{CD}^{+} \mathrm{T}$-cell anergy when given to tumor-bearing mice before adoptive transfer of tumorspecific T-cells (38). Finally, immunization with peptide-loaded DCs treated with siRNA for SOCS1 and TLR ligands induced strong immunity against the self-antigen Trp2 leading to vitiligo and rejection of melanoma tumors (36).

Ex vivo manipulation of anergic tumor-antigen specific T-cells represents an additional strategy to overcome this state of unresponsiveness. Studies in mice expressing gag as self-antigen in the liver, demonstrated that antigen-specific $\mathrm{CD} 8^{+} \mathrm{T}$-cells are tolerant and unable to mount a 
response to immunization in vivo. However, repeated ex vivo stimulation of these T-cells with cognate antigen resulted in a population capable of rejecting a gag-expressing leukemia upon their adoptive transfer and concurrent treatment with IL-2 and chemotherapy in vivo (22). A similar outcome was also achieved when anti-gag specific $\mathrm{CD} 8^{+} \mathrm{T}$-cells were primed and expanded in vitro with IL-15 (49). Therefore, in spite of the sobering findings pointing to tolerance to tumor antigens as a critical immunosuppressive mechanism that has undoubtedly raised the bar for cancer immunotherapy, a breeze of optimism has recently involved this field given the encouraging results that tolerance to tumor antigens can be safely broken in cancer patients.

\section{Immunosuppressive Strategies Employed by Tumors to Evade T-cell Responses}

Cancer cells display multiple immunosuppressive mechanisms to evade T-cell responses, either to avoid immune recognition or to disable effector T-cells $(2,50,51)$. These include alterations of components of the antigen presentation machinery, defects in proximal TCR signaling, secretion of immunosuppressive and proapoptotic factors, activation of negative regulatory pathways and specific recruitment of regulatory cell populations $(2,27,52,53)$ (Fig. 2 ). These mechanisms are suggested to cooperate in advanced stages of cancer to limit the ability of the immune system to restrain the tumor and the effectiveness of immunotherapy strategies to successfully eradicate malignant cells (54). Understanding the spatiotemporal regulation of these mechanisms might contribute to overcome the tolerizing conditions imposed by the tumor immunosuppressive microenvironment.

\subsection{Abnormalities in the antigen presentation machinery}

One of the best studied mechanisms used by tumors to avoid T-cell recognition is through impaired antigen presentation (55). It has been observed that the continuous generation of tumor variants by increased frequency of mutations and/or genetic deletions can result in escape from T-cell recognition (52). In this regard, cancer cells that no longer express the tumor antigen may escape destruction by CTLs and grow progressively. However, recent findings indicate that CTLs may indirectly eliminate these tumor variants when tumor cells express sufficient antigen to be effectively cross-presented by the tumor stroma (56).

In addition to the generation of antigen loss variants, downregulation of the antigen processing machinery has been documented extensively at different levels in a wide variety of tumors and has been considered as the most common strategy exploited by tumors cells to escape T-cell control $(2,55)$. Complete absence of MHC-I expression caused by mutations or alternations of the reading frameshift of the $\beta 2$ microglobulin $(\beta 2 \mathrm{~m})$ gene, and decreased MHC-I expression due to transcriptional regulation (57-60) prevents recognition by effector CTLs. Furthermore, point mutations and gene deletions lead to selective loss of individual HLA alleles (61), which facilitates immune evasion from T-cell responses. These changes have been frequently observed in renal cell carcinoma, colorectal carcinoma and melanoma $(51,55)$. However, MHC-I downregulation may in turn sensitize tumors for NK-cell attack and, consequently, tumors might display alternative mechanisms to evade NK-cell mediated recognition (62). NK cells express activating receptors, such as NKG2D, which bind to the stress-induced ligands MICA and MICB that are expressed in a number of tumors (62). Activation of NK cells through this signaling pathway can overcome the inhibitory effect of HLA class-I binding receptors (KIRs). Thus, although HLA class-I negative tumors should be susceptible to NK cell-mediated killing, downregulation or shedding of MICA or MICB may represent a novel mechanism of tumor-immune escape (63). Recently Dranoff and colleagues demonstrated that anti-MICA antibodies generated in response to a combined immunotherapy strategy are associated with a 
reduction of circulating soluble MICA and augmentation of NK- and $\mathrm{CD} 8^{+} \mathrm{T}$-cell-mediated cytotoxicity (64).

Interestingly, impaired presentation of tumor antigens is also achieved by defects in the antigen processing machinery, including mutations of the transporter-associated with antigen processing (TAP) and components of the immunoproteasome such as LMP2 and LMP7 (reviewed in 55,57). These mutations can change the spectrum of peptides presented by MHCI molecules. In most cases, expression of these components can be restored by treatment of tumor cells with IFN- $\gamma$, suggesting a reversible inhibition of gene transcription (57). Since a number of excellent reviews have been recently devoted to tumor-immune escape mechanisms involving defects in antigen presentation $(51,55,57)$, we will not discuss in detail these mechanisms and will directly focus on active immunosuppressive strategies developed by tumor cells.

\subsection{Defects in proximal TCR-mediated signaling}

Impairment of T-cell signaling has been detected in long-term tumor-bearing mice and patients with different types of tumors (51). A marked decrease has been observed in the expression of $\mathrm{CD} 3 \zeta$ chain, $\mathrm{p} 56^{\mathrm{lck}}$ and $\mathrm{p} 59^{\text {fyn }}$ tyrosin kinases in tumor-infiltrating lymphocytes (TILs), all of which play critical roles in proximal signaling events leading to T-cell activation $(51,65)$. Recent clinical work confirmed these defects in CTLs and NK cells from patients with melanoma, colon, breast and prostate carcinoma $(51,57)$. Koneru and colleagues recently showed that impaired proximal TCR signaling inhibits CTL lytic function and inactivates the effector phase of antitumor responses (66). The authors found that signal transduction is blocked in freshly isolated nonlytic TILs at an early stage of activation as a result of the activity of the inhibitory phosphatase Shp-1 (66). Thus, cognate interactions between tumor and immune cells may result in blockade of proximal TCR signals and dependent lytic functions. Whether an integrated immunosuppressive network at the tumor site may contribute to defects in TCR signals still remain to be elucidated.

\subsection{Tumor-induced immunosuppression through secretion of immunoregulatory cytokines: interaction with downstream signaling pathways}

A number of biologically active agents (including cytokines and growth factors) either synthesized by tumor or stromal cells exert suppressive effects on the immune system (67). TGF- $\beta$ is a pleiotropic immunosuppressive cytokine that inhibits T-cell activation, proliferation and differentiation (68). Early studies have shown that transfection of TGF- $\beta_{1}$ cDNA into highly immunogenic tumors promotes tumor escape from the immune system (69). Furthermore, elevated serum TGF- $\beta$ levels have been shown to be associated with poor prognosis in a number of malignancies, including prostate, gastric and bladder carcinoma (reviewed in 2). Gorelik \& Flavell used genetically engineered $\mathrm{CD}^{+} \mathrm{T}$ cells to demonstrate that T-cell-specific blockade of TGF- $\beta$ signaling can allow the generation of, an otherwise repressed, tumor-specific CTL response (70). Most recently, Thomas and Massague demonstrated that TGF- $\beta$ acts on CTLs to specifically repress the expression of different cytolytic gene products; namely perforin, granzyme A, granzyme B, Fas ligand (Fas L), and IFN- $\gamma$, which are collectively responsible for CTL-mediated tumor cytotoxicity (71). In addition, antibody-mediated neutralization of TGF- $\beta$ restored expression of these genes in tumor-specific CTLs, leading to tumor clearance in vivo. Recent observations from Ahmadzadeh et al. confirmed these findings in an in vitro examination of $\mathrm{CD}^{+} \mathrm{T}$-cells from patients who received a melanoma vaccine (72). These cells showed impaired effector functions when TGF- $\beta$ was present in T-cell cultures.

Additional mechanisms of TGF $\beta$-induced immunosuppression have also been reported. Terabe et al showed that CD1d-restricted natural killer T (NKT) cells can suppress effective CTL 
responses through mechanisms involving IL-13 and TGF- $\beta$ production and activation of the IL-4R-STAT6 pathway (73). Therefore, blockade of TGF- $\beta$ signaling not only enhances the frequency of anti-tumor CTLs, but also restores the activities of the cytolytic machinery and IFN- $\gamma$ production and counteracts NKT cell-mediated immunosuppression. Several therapeutic approaches have been explored to counteract TGF- $\beta$-mediated immunosuppression, including administration of an anti-TGF $\beta$ R 2 monoclonal antibody and small molecule drugs that inhibits the ATP-binding site of TGF $\beta$ R 1 and interrupt TGF- $\beta$-mediated Smad3 and Smad4 signaling (74).

In addition to TGF- $\beta$, other biologically active agents are present in the tumor microenvironment and have been shown to impair immune cell function including IL-10 (31, 75), prostaglandin $\mathrm{E}_{2}\left(\mathrm{PGE}_{2}\right)(76)$ and sialomucins (77). IL-10 is abundant in the tumor microenvironment, impairs DC functionality (31) and protects tumor cells from CTL-mediated cytotoxicity by downregulating TAP1 and TAP2 (75). However, in contrast to previous assumptions, recent evidence indicates that IL-10 may also possess immunostimulating properties. Unexpectedly, overexpression of IL-10 in the tumor microenvironment synergizes with other cytokines to promote tumor rejection instead of inducing immunosuppression (78, 79). Remarkably, it has been speculated that immunosuppressive cytokines and proapoptotic factors elaborated by tumor or stromal cells may not be necessarily tumor-immune escape mechanisms, but may instead contribute other biological functions including cell growth regulation, migration and angiogenesis (52).

Mounting evidence supports the idea that immune cells and inflammatory mediators (cytokines, chemokines) within the tumor microenvironment, can either be beneficial or detrimental for tumor progression (80). Karin and colleagues found that activation of the nuclear factor- $\mathrm{KB}$ (NF- $\mathrm{\kappa B}$ ) transcription factor through the classical IKK $\beta$-dependent pathway critically regulates the decision between inflammation-induced tumor growth and immunemediated tumor rejection (81). The authors demonstrated that inhibition of NF- $\mathrm{kB}$ in cancer cells converts inflammation-induced tumor growth to tumor regression (81). Thus, perception of different inflammatory mediators (cytokines, chemokines and growth factors) as promoters of carcinogenesis or tumor rejection may depend on the intracellular signals triggered by these biologically active agents in the tumor microenvironment. In this regard, it has been recently showed that tumors can inhibit the sensing of danger signals, thereby converting inflammatory response to those that could instead promote tumor escape (33). In very elegant experiments, Wang and colleagues demonstrated that oncogenic signaling pathways, such as Stat 3, can actively modulate tumor cell evasion of immune responses by inhibiting the production of proinflammatory danger signals (33). Targeted disruption of Stat3 signaling in tumor cells resulted in up-regulation of proinflammatory cytokines and chemokines genes, including TNF$\alpha$, IFN- $\beta$ and IP-10 (33). The critical role of Stat 3 signaling in restraining multiple anti-tumor effector mechanisms defines this signaling pathway as one of the most attractive targets to potentiate innate and adaptive immunity in the tumor microenvironment.

\subsection{Negative costimulatory pathways: immunological checkpoints in the tumor microenvironment}

Effective modulation of antitumor responses requires the blockade of negative immunological checkpoints that may interrupt effector T-cell responses $(54,67)$. Undoubtedly, one the best studied negative immunological checkpoints is the cytotoxic T lymphocyte antigen-4 (CTLA-4/CD152) which has been introduced in previous sections $(41-43,82)$. CTLA-4 inhibits T-cell activation and IL-2 production through binding to B7 costimulatory molecules with higher affinity than $\mathrm{CD} 28$. Allison and colleagues were pioneers in demonstrating that blockade of B7-CTLA-4 interactions enhance the antitumor immune response (82). Further work supported the concept showing that antibody-mediated blockade of CTLA-4 enhances 
the antitumor immunity provided by a GM-CSF-transduced vaccine $(42,43,64)$. This combined strategy proved to be successful in experimental models of established tumors and patients with malignant melanoma (41-43). In most cases, CTLA-4 blockade was accompanied by the appearance of autoimmune manifestations including enterocolitis, vitiligo, hypophysitis, and hepatitis $(42,43)$. An interesting finding by Dranoff's group was the demonstration of the efficacy of CTLA-4 blockade in patients who had previously been vaccinated with GM-CSFsecreting tumor cells (83). Most recently, Quezada et al. showed that CTLA-4 blockade in combination with GM-CSF vaccination alters the intratumor balance of effector and regulatory T-cells (84). These results unambiguously place CTLA-4 as a major inhibitory pathway in the tumor microenvironment.

Another immunological checkpoint that contributes to tumor cell evasion involves the interactions between programmed death-1 (PD-1) and programmed death receptor ligand 1 (PD-L1) (53). PD-1 was first identified by Honjo and colleagues as a 55-kDa type-I transmembrane receptor in a murine T-cell hybridoma clone undergoing activation-induced cell death (AICD) (85). The inhibitory activity of PD-1 was confirmed by the autoimmune phenotype of PD-1-deficient mice (86). PD-1 can bind to PD-L1 (also called B7-H1) and to PD-L2 (also called B7-DC) resulting in most cases in inhibition of T-cell activation (87). While the intimate mechanisms involved in the inhibitory effects of PD-1/PD-L1 interactions still remain obscure, it appears that the cytoplasmic tail of PD-1 contains an immunoreceptor tyrosine-based inhibitory motif (ITIM) and an immunoreceptor tyrosin-based switch motif (ITSM) (53). PD-1 ligation induces ITIM phosphorylation and recruitment of the phosphatase Src homology region 2-containing protein tyrosine phosphatase-2 (SHP-2) (53). Dong et al. found that PD-L1 is expressed by different tumor types, including breast, ovary and colon carcinomas and its expression is up-regulated in the presence of IFN- $\gamma$ (88). Tumor-cell surface PD-L1 inhibits immune responses by promoting apoptosis of effector CTLs via induction of Fas ligand (Fas L) and IL-10. Furthermore, PD-L1 overexpression in the murine mastocytoma P815 leads to decreased tumor cell lysis by a tumor-specific CTL clone (88). In addition, antibody-mediated PDL-1 blockade reduced T-cell apoptosis leading to heightened T-cellmediated tumor rejection in different tumor models $(88,89)$. Furthermore, studies from Blank et al. clearly demonstrated, using PD-1-deficient TCR transgenic T-cells, the ability of PD-L1 to inhibit the effector phase of tumor rejection (90). In addition, blockade of PD-1/PD-L1 interactions improved DC-mediated antitumor activity in vivo, suggesting another cellular target of PD-1-mediated negative regulation (91). Thus, targeted therapies aimed at interrupting PD-1/PD-L1 interactions will be useful to potentiate effector anti-tumor responses.

Although PD-1 engagement usually leads to the transduction of inhibitory signals, positive costimulatory roles for PD-L1 and PD-L2 have also been reported $(53,92)$. In this regard, Shin et al. showed that PD-L2 (B7-DC)-deficient mice have impaired antigen-specific CTL function along with increased tumor growth (92). These discordant results regarding the positive or negative effects of PD-L1 and PD-L2 signaling might be explained by the presence of alternative PD-L1 or PD-L2 receptors which could be expressed with different kinetics on different T-cell subpopulations. In this regard, it will be of interest to investigate whether simultaneous blockade of distinct inhibitory pathways including PD-1/PD-L1, B7/CTLA-4 and Stat 3 will have synergistic effect in stimulating anti-tumor immunity and promoting tumor regression. Recently, Barber and colleagues elegantly demonstrated a critical role for the PD-1/ PD-L1 inhibitory pathway in functional impairment of antigen-specific T-cells in vivo (93). The authors found that blockade of PD-L1/PD-1 interactions restored the ability of CD8 ${ }^{+} \mathrm{T}$ cells to kill target cells (93). However, blockade of CTLA-4 had no effect on CTL-mediated target killing. These results suggest no significant overlap between the inhibitory signals provided by PD- 1 and CTLA- 4 . 
In this regard, Watanabe and colleagues identified a third inhibitory receptor on T-cells: "the B- and T-lymphocyte attenuator (BTLA)" with similarities to CTLA-4 and PD-1 (94). Interestingly, BTLA is not expressed by naïve T-cells, but is induced during T-cell activation and remains expressed on T helper (Th)-1 but not Th2 cells (94). Whether BTLA contributes to tumor-immune escape remains to be investigated. Similarly, Kryczek et al. recently identified B7-H4 as a novel marker of a population of suppressor macrophages in human ovarian carcinoma (95). Blockade of B7-H4 restored T-cell stimulatory capacity of macrophages (95). Thus, targeting inhibitory costimulatory signals may represent a promising strategy to overcome immunosuppression, thereby augmenting specific T-cell mediated tumor immunity in response to immunotherapy.

\subsection{Immunosuppression through modulation of tryptophan catabolism}

One mechanism that may contribute to the establishment of immune tolerance in the tumor microenvironment is the immunoregulatory enzyme indoleamine 2,3-dioxygenase (IDO). This is a heme-containing enzyme which catalizes the oxidative breakdown of the essential amino acid tryptophan, via de kynurenine pathway (96). The first evidence showing that IDO might play a role in the establishment of immune privilege was provided by Munn and colleagues who demonstrated that IDO preserves the fetoplacental unit from T-cell attack (97). This effect was confirmed by in vitro observations showing inhibition of T-cell proliferation and blockade of cell cycle progression by tryptophan depletion (96).

The fact that IDO is also expressed by different tumor cells prompted Uyttenhove and colleagues (98) to investigate the role of IDO in the establishment of tumor-immune escape. The authors demonstrated that immunogenic tumors engineered to overexpress IDO grew more aggressively in immunocompetent hosts and this effect correlated with a decreased accumulation of activated T-cells at the tumor site (98). Importantly, in vivo administration of the IDO inhibitor 1-methyltryptophan resulted in reduced tumor mass and stimulation of antitumor CTL responses (98). Although the precise mechanisms that regulate IDO expression and function still remain to be ascertained, Muller and colleagues recently showed that IDO is under the genetic control of the tumor suppression gene Binl, which is attenuated in many human tumors. Using a mouse knockout model, the authors showed that Binl can restrain immune escape of oncogenically-transformed cells by restricting expression of IDO (99). Finally, the authors found that small-molecule inhibitors of IDO cooperate with chemotherapeutic agents to elicit regression of established tumors refractory to single-agent therapy (99).

Whether IDO plays a physiological role in peripheral T-cell tolerance still remains to be elucidated. In contrast to other critical homeostatic mediators such as CTLA-4 or PD-L1, IDOdeficient mice do not display lymphoproliferative disease or autoimmunity, suggesting that IDO might be predominantly involved in the generation of local immune tolerance at selected immune privilege sites, including fetoplacental tissue and tumor microenvironments. Thus, pharmacological blockade of IDO may be an important component of combinatorial immunotherapy strategies.

\subsection{The "tumor counterattack" hypothesis: a dilemma to be solved}

One of the most controversial mechanisms of tumor-induced immunosuppression is the expression of death receptor ligands (e.g FasL, TRAIL) by cancer cells. FasL was first identified in 1993 as a $40 \mathrm{kDa}$ type-II transmembrane protein belonging to the TNF family (100). FasL can interact with its receptor Fas and trigger a cascade of subcellular events leading to the induction of apoptotic cell death of sensitive target cells (100). Fas/FasL interactions play important roles in cytotoxic T-cell responses, activation-induced cell death (AICD), and maintenance of immune privilege $(100,101)$. 
In addition, it has been speculated that acquisition of FasL may enable cancer cells to deliver death signals to activated Fas-positive T-lymphocytes (102-105). Supporting this hypothesis is the observation that human tumor cells of diverse origin, including melanoma, gastric carcinoma, astrocytoma and lymphoma express FasL (105). Furthermore, T-cell apoptoiss has been found in situ associated with FasL-expressing tumors (105).

In 1996, Hahne et al. reported the ability of FasL to confer immune privilege to tumor cells in vivo (102). The authors found that injection of FasL-positive melanoma cells was substantially delayed in mice with a mutated Fas receptor, supporting in vivo the concept that tumor cells may eliminate effector T-cells through a FasL-dependent mechanism (102).

However, despite the wealth of data accumulated in support of the FasL counterattack hypothesis, many contradictory studies have been reported showing that FasL can also have proinflammatory and antitumoral effects in some contexts (52). FasL gene delivery to sites of tumor growth resulted in increased tumor rejection instead of tumor-immune escape, an effect which was accompanied by increased infiltration of inflammatory neutrophils (106). In addition, after screening a panel of melanoma cell lines by reverse transcriptase-PCR and functional assays, Chappell et al. concluded that none of these cells expressed functional FasL and indicated potential cross-reactivity of the anti-FasL antibodies used in the original experiments (107).

To reconcile these conflicting findings, it has been hypothesized that the maintenance of immune privilege in tumor relies on the collective production of inhibitory signals, such as TGF- $\beta$, that may create an appropriate setting to prevent the pro-inflammatory effects of FasL, thus favoring immune escape by eliminating anti-tumor effector cells (106). In addition, it has been speculated that the local levels of FasL might also influence the final outcome; while higher levels of FasL (ie. induced by Fas L gene delivery) may lead to neutrophil inflammation, physiological levels may be sufficient to delete anti-tumor lymphocytes and promote tumor escape. Nonetheless, the debate is still alive. Ryan et al. recently showed that down-regulation of FasL expression in colon cancer cells significantly reduced tumor growth in syngeneic immunocompetent mice and stimulated the development of a T-cell mediated anti-tumor response (108), providing novel support in favor of the "Fas counterattack" hypothesis. Interestingly, Andreola and colleagues refined this hypothesis reporting a novel mechanism of tumor counterattack through the secretion of microvesicles expressing functional FasL (104). The authors showed that melanoma cells express FasL intracellularly with a localization confined to multivesicular bodies. During tumor progression, FasL-containing microvesicles can be released extracellularly and induce apoptosis of Fas-sensitive lymphoid cells (104). These results led to the realization that tumors may be capable of triggering death of immune effector cells located at distant sites from the tumor microenvironment through the release of FasL-bearing microvesicles (109). Adding complexity to this controversial mechanism, it has been proposed that Fas/FasL interactions may promote AICD of anti-tumor T-cells. Upon tumor recognition and activation, T-cells may express substantial levels of FasL, which will induce "suicidal" or "fratricidal" cell death (52). Further, Lugini et al. recently reported an intriguing observation showing that human metastatic melanoma cells may even engulf and ingest live T-lymphocytes through a process called "tumor cannibalism" (110).

In addition to FasL-mediated counterattack, other molecules including the death ligand TRAIL (111) and the chemokine RANTES (112) have also been involved in tumor-induced cell death. In addition, certain tumors express RCAS1 (receptor-binding cancer antigen expressed on Siso cells), which induces cell cycle arrest and apoptosis of activated T-cells expressing functional RCAS1 receptors (113). Finally, Chahlavi et al. recently showed that glioblastoma cells induce T-cell death through distinct mechanisms involving gangliosides and CD70/CD27 interactions (114). Interestingly blockade of CD70, but not TNF- $\alpha$ or Fas protected effector T-cells from 
tumor-induced cell death (114). Collectively, these observations suggest that multiple mechanisms may contribute to T-cell dysfunction observed within the tumor microenvironment. Whether different "counterattack" strategies may prevail in individual tumor cell types still remains to be investigated.

\subsection{Regulatory T- cells in the establishment of tumor-immune privilege}

Significant interest has recently focused on the premise that tumors may subvert tumor immunity by promoting the expansion, recruitment and activation of regulatory T-cell populations $(115,116)$. CD $4^{+} \mathrm{CD} 25^{+}$T-regulatory cells (Tregs) were identified by Sakaguchi and colleagues as a naturally occurring $\mathrm{CD} 4^{+} \mathrm{T}$-cell subset (comprising 5-10\% of all peripheral $\mathrm{T}$-cells) constitutively expressing CD25 that suppresses T-cell responses in vitro and in vivo (114). It has been suggested that the forkhead box P3 (FOXP3) transcription factor represents a reliable intracellular marker for naturally occurring Tregs, in combination with other markers including CTLA-4, glucocorticoid-induced TNF receptor (GITR), lymphocyte activation gene-3 (LAG-3) and neuropilin $(115,116)$.

Mounting evidence indicates that Tregs play a key role in restraining anti-tumor immunity (115). A high number of $\mathrm{CD}^{+} \mathrm{CD} 25^{+} \mathrm{FOXP} 3^{+}$cells is found in lung, pancreatic, breast, liver, ovary and skin cancer patients either in the circulation or in the tumor itself (115). In a very elegant study, Curiel and colleagues recently provided proof of principle of the critical role of $\mathrm{CD} 4^{+} \mathrm{CD} 25^{+} \mathrm{FOXP} 3^{+}$cells in promoting tumor-immune privilege (117). The authors found that large numbers of $\mathrm{CD} 4^{+} \mathrm{CD} 25^{+} \mathrm{FOXP} 3^{+}$cells in tumors and malignant ascites, but not in tumor-draining lymph nodes inversely correlate with the survival of patients with malignant ovarian carcinoma (117). Interestingly, the authors advanced a step forward demonstrating that Tregs migrate into the tumor site under the influence of the chemokine CCL22, providing convincing evidence that Tregs create a favorable environment for tumor escape (117).

How can we overcome the suppressive effects of Tregs? Pioneer studies revealed that depletion of $\mathrm{CD} 4{ }^{+} \mathrm{CD} 25^{+}$Tregs using anti-CD25 monoclonal antibodies results in heightened T-cellmediated tumor rejection $(118,119)$. Supporting these findings, Turk and colleagues demonstrated that selective depletion of Tregs in tumor-bearing mice results in CD8 ${ }^{+} \mathrm{T}$-cellmediated tumor rejection and concomitant immunity to a poorly immunogenic tumor (120). Furthermore, treatment with anti-GITR agonistic antibodies has been shown to overcome tolerance to tumor antigens by either attenuating the suppressive activity of Tregs or costimulating effector T-cell functions (121).

An interesting therapeutic approach for depletion of Tregs is the use of denileukin diftitox (Ontak) which is a ligand toxin fusion consisting of full-length IL-2 fused to the enzymatically active and translocating domains of diphtheria toxin (116). This complex is internalized into $\mathrm{CD} 25^{+}$cells by endocytosis. The ADP ribosyltransferase activity of diphtheria toxin is cleaved and translocated into the cytosol, where it inhibits protein synthesis, leading to apoptosis (116). Furthermore, a recent study described a novel mechanism by which Toll-like receptors (TLRs), particularly TLR8 engagement, can reverse the function of Tregs $(122,123)$, suggesting that natural or synthetic TLR ligands may also serve as potential drug targets to overcome regulatory T-cell function in cancer. Moreover, cyclophosphamide treatment has been shown to inhibit Tregs by selectively depleting the cycling population of $\mathrm{CD} 4{ }^{+} \mathrm{CD} 25^{+}$ cells (124).

In addition to naturally-occurring Tregs, other regulatory cell populations may also contribute to impaired tumor surveillance in cancer patients. In this regard, IL-10-producing Treg cells (Tr1) have raised considerable attention $(125,126)$. Recent studies showed that exposure of DC to myeloma cell lysates results in increased IL-10 production which in turn favors the expansion of $\operatorname{Tr} 1$ cells (127). In addition, $\mathrm{CD} 4^{+}$NKT cells constitute another 
immunosuppressive cell population in the tumor microenvironment which suppresses CTLeffector functions by secreting IL-13 and TGF- $\beta$ (73). Thus, different regulatory cell populations may be recruited and activated at the tumor site to disarm T-cell effector mechanisms and tilt the balance toward an immunosuppressive tumor microenvironment. Harnessing the immune system by eliminating immunoregulatory cells is currently a major concern of tumor immunologists.

\subsection{Protein-glycan interactions in tumor-immune escape}

Protein-glycan interactions play critical roles in several aspects of cancer biology including metastasis, cell migration, angiogenesis and inflammation (128) Galectins are evolutionarilyconserved glycan-binding proteins defined by their affinity for $\mathrm{N}$-acetyllactosamine sequences which can be displayed on both $\mathrm{N}$ - and O-glycans on cell surface glycoconjugates (128). Through binding to these glycoconjugates, galectins can deliver signals intracellularly and modulate different biological processes including cell survival, angiogenesis and inflammation (126). To date, 15 mammalian galectins have been identified, 11 of which have human orthologues. Galectins are present in tumor cells and cancer-associated stroma in different tumor types, including melanoma, glioma, gastric cancer and breast carcinoma (129). In general, expression of these proteins correlates with the aggressiveness of the tumors and the acquisition of metastatic phenotype, indicating that galectins might modulate tumor progression and influence disease outcome (129).

Galectin-1, a member of the galectin family, has the potential to inhibit T-cell effector functions by inducing T-cell apoptosis (130), sensitizing T-cells to FasL-induced cell death (131), blocking proximal TCR signals (132) and suppressing Th1 and pro-inflammatory cytokine secretion (133). It has been shown that the regulated expression of glycosyltransferases during $\mathrm{T}$-cell development and activation, creating $\mathrm{N}$-acetyllactosamine ligands, may determine $\mathrm{T}$ cell susceptibility to galectin-1 (reviewed in 134).

Prompted by these observations, we have investigated whether tumor secretion of galectin-1 might contribute in tilting the balance toward an immunosuppressive environment at the tumor site. Using in vitro and in vivo experiments we found that human and murine melanoma cells secrete functional galectin-1, which substantially contributes to the immunosuppressive activities of these tumor cells (135). Targeted inhibition of galectin-1 gene expression in vivo rendered mice resistant to tumor challenge and allowed the generation of tumor-specific Th1-type responses in tumor-draining lymph nodes (135). Given its profound effects on tumorinduced immunosuppression, galectin-1 may be an attractive target for therapeutic intervention in cancer.

Additionally, other members of the galectin family such as galectin-2, -3 and -9 have been shown to negatively affect T-cell survival, activation and cytokine secretion (136-139). Particularly interesting, Zhu and colleagues recently showed that galectin-9 can act as a ligand of Tim-3, a Th1-specific cell surface molecule and negatively regulate Th1 responses (138). In addition, Demetriou and colleagues found that multivalent complexes composed of galectin-3 and specific N-glycans may restrict the lateral mobility of TCR complexes and restrain TCR-mediated signal transduction (139). Thus, it is becoming increasingly apparent that galectins may contribute to immunoregulation by tuning the initiation and resolution of $\mathrm{T}$-cell responses. The increased understanding of the role of galectin-sugar interactions in cancer-induced immunosuppression should provide insights into how the regulation of galectin expression might be exploited for therapeutic purposes. 


\section{Dendritic Cells: Key Players in the Immunosuppressive Network Displayed by Tumor Cells}

DCs are critically important for the generation and maintenance of anti-tumor immune responses (140). It is now well established that tumor cells contain a large number of antigens that can be recognized by the host immune system. DCs can take up, process, and present tumor antigens to activate a tumor-specific T-cell response. However, this does not happen in most types of cancer or in animal models with spontaneously arising tumors. Instead of being eliminated by an immune response, tumors progress, metastasize and ultimately kill the host. We will highlight in this section the most important strategies by which DCs contribute to the immunosuppressive network, thus leading to tumor escape and failure of immunotherapy strategies.

DCs are developed in the bone marrow from hematopoietic progenitor cells (HPC) under the control of a complex network of soluble and cell-bound molecules produced and expressed by bone marrow stroma (140). Most DCs differentiate along the myeloid lineage, and precursors of DCs include common myeloid progenitor cells (CMP) and immature myeloid cells (IMC). DCs can also differentiate from common lymphoid progenitor cells (CLP). The proportion of lymphoid DCs is substantially lower than that of myeloid DCs, and most of these cells belong to a relatively rare subset of DCs known as plasmacytoid DCs (pDCs). However, recent studies have established that pDCs can be generated not only from CLPs, but also from CMPs (141). pDCs express lymphoid antigens and produce large amounts of type-I IFN in response to viruses. They have a lower ability to process and present antigen and stimulate T-cells than myeloid DCs. In humans, myeloid DCs are characterized by a lack of expression of lineagespecific markers and the expression of CD11c, whereas pDCs do not express lineage-specific markers or CD11c, but express a receptor for IL-3 (IL-3R). In vitro, myeloid DCs are dependent on GM-CSF, and pDCs are dependent on IL-3 and IFN- $\alpha$ for survival (142). DCs that leave the bone marrow are defined as immature DCs (iDCs). iDCs have little or no expression of costimulatory molecules such as CD80, CD86 and CD40 on the surface and produce little or no IL-12, which is required to support T-cell proliferation. However, these cells are capable of taking-up and processing various molecules and microorganisms. In tumor tissues, antigens may come from dying tumor cells. DCs can engulf apoptotic or necrotic tumor cells, and process and present tumor-associated antigens on their surface. Different microbial and viral products, necrotic cells including tumor cells, double-stranded RNA and other factors can activate DCs. This effect is clearly manifested by up-regulated expression of MHC-II and costimulatory molecules, increased IL-12 production and enhanced stimulation of antigenspecific T-cell responses $(143,144)$. Data from many laboratories obtained during the past few years indicates that defects in the DC system are one of the main factors responsible for tumor escape, which contributes in various ways to the T-cell defects in cancer. These abnormalities manifest in several major phenomena.

\subsection{Decreased presence of functionally competent DCs}

Tumor-bearing mice have been shown to have decreased numbers and function of DCs in lymph nodes, spleen and skin $(145,146)$. Large numbers of studies in cancer patients have found similar effects. We have described decreased presence of DC populations in patients with squamous cell carcinoma of the head and neck (HNSCC). Patients with early stages of the disease had more than 2-fold and patients with advanced disease more then 4-fold fewer DCs in peripheral blood than control healthy donors (147). In more recent studies significant reduction in the number of DCs was demonstrated in patients with HNSCC (148). In these studies, both myeloid and lymphoid populations of DCs were investigated. A significant decrease was observed only in the myeloid population of DCs, whereas pDCs were not affected. Most recent studies have evaluated circulating DCs in 136 patients with breast cancer, prostate 
cancer, and malignant glioma. Patients had significantly fewer circulating myeloid DCs and pDC, and a concurrent accumulation of immature DCs. Immature DCs had reduced capacity to capture antigens and elicited poor proliferation and IFN- $\gamma$ secretion by T-lymphocytes (149). Several clinical studies have provided clear evidence that surgical removal of tumors can increase the number of DCs in the peripheral blood of patients with cancer. We have demonstrated an increase in the total DC population in patients with breast and prostate cancer after surgery (147). The functional consequences of the decreased number of functionally competent DCs in patients with cancer are obvious: a decreased number of APCs makes immune stimulation less effective. However, it is likely that other manifestations of the defective DC differentiation and activation have more profound effects on antitumour immune responses.

\subsection{Accumulation of immature DCs in cancer}

In patients with cancer, it has been repeatedly shown that tumors contain cells with phenotype of iDCs. For example, Troy et al. have shown that DCs are not recruited in large numbers into renal cell carcinomas, and that the low number of DCs that can be recovered from these tumors are minimally activated and have reduced allostimulatory activity (150). These DCs express low levels of the co-stimulatory molecules CD80 and CD86. Furthermore, DCs derived from progressing melanoma metastases do not express CD86 at all (151). Similar data was obtained for DCs isolated from basal cell carcinomas (152). Less than $1 \%$ of the intratumoural DCs and only approximately $10 \%$ of the peritumoral DCs expressed either CD80 or CD86. DCs harvested from BCC had reduced APC function. Chaux et al. reported that less than $10 \%$ of DCs isolated from colon carcinomas express CD80 or CD86 (153). Importantly, the addition of GM-CSF and TNF- $\alpha$, or CD40L to in vitro cultures, all of which are normally potent stimulators of CD80/CD86 expression, did not induce CD80 expression on tumor-infiltrating DCs. This indicates that the lack of CD80/CD86 expression does not simply result from a lack of activation of these cells in the tumor microenvironment but might be caused by defects in cell differentiation (153). Consistent with these observations, an increased proportion of iDCs with reduced expression of co-stimulatory molecules was found in the peripheral blood of patients with breast, head and neck, lung, and esophageal cancers and similar data has been obtained in mouse tumor models (146-154). Immature DCs are unable to induce antitumour immune responses and can induce T-cell tolerance. It has been shown that if APCs fail to provide an appropriate co-stimulatory signal for T cells, tolerance or anergy can develop (27, 140). DCs derived from colon cancer tissue or melanoma-associated DCs were not only significantly less potent inducers of T-cell proliferation, but also induced T-cell anergy (151153). It has been demonstrated that in vivo delivery of antigen into non-activated DCs in tumorfree mice results in the induction of $\mathrm{CD} 8^{+} \mathrm{T}$-cell tolerance (155). Since these non-activated DCs resemble iDCs, it is possible that similar mechanisms might take place at certain stages of tumor growth. Specific experiments, probably in transgenic tumor models, need to be designed to directly address this question in vivo.

\subsection{Accumulation of tolerogenic DCs in cancer}

In addition to accumulation of iDCs, a number of studies reported the presence in tumor tissues of subsets of DCs with potential to suppress T-cells. Most prominent of them are pDC (156). As we described above in contrast to myeloid DCs, the number of circulating pDC in patients with different types of cancer was not changed. Furthermore, accumulation of pDCs was found inside ovarian tumors. This accumulation was attributed to stromal-derived factor-1 (SDF-1) secreted by malignant cells. Tumor associated pDCs induced IL-10 production by T-cells (157). pDCs also infiltrated tumor tissue of patients with HNSCC. The ability of these pDCs to produce IFN- $\alpha$ was diminished. Tumor-induced down-regulation of TLR9 was identified as one mechanism probably contributing to impaired $\mathrm{pDC}$ function within the tumor environment (158). Accumulation of pDCs was also found in peritumoral areas of primary melanomas 
(159). It has been shown that mouse tumor-draining lymph nodes contained a subset of pDCs that constitutively expressed immunosuppressive levels of the enzyme IDO. This may prevent the clonal expansion of T-cells and promote T-cell death. Despite comprising only $0.5 \%$ of LN cells, pDCs potently suppressed T-cell responses to antigens presented by the pDCs themselves and also, in a dominant fashion, suppressed T-cell responses to third-party antigens presented by nonsuppressive APCs. Adoptive transfer of these DCs into naive hosts created profound local T-cell anergy (160). The expression of IDO in myeloid DC has been described for both human and murine DCs (29). The appearance of $\mathrm{IDO}^{+} \mathrm{DC}$ could be demonstrated in vivo in breast tumor tissue as well as draining lymph nodes in patients with melanoma, breast, colon, lung and pancreas cancers (96). Treatment with CTLA-4-immunoglobulin fusion protein was found to upregulate the levels of immunoreactive IDO only by certain subsets of mouse APC in the spleen. This response was restricted mainly to cells in the B220 $(\mathrm{pDC})$ and CD8 $\alpha^{+}$ populations of splenic DCs (161). Studies with APC fractions that were isolated from mice exposed to CTLA-4-immunoglobulin confirmed that IDO-dependent T-cell suppression was confined to specific DC subsets that express these markers (162). Further evaluation will be needed to clarify whether these results describe a single 'IDO-competent' population of cells that expresses both markers (that is, $\mathrm{B} 220^{+} \mathrm{CD} 8 \alpha^{+} \mathrm{DCs}$ ) or several different populations within the complex mixture of DC subtypes in the spleen. However, an important point is that many more cells express the target ligands for the CTLA-4-immunoglobulin fusion protein than actually showed up-regulation of IDO expression. A detailed analysis of IDO-mediated T-cell suppression in tumor-draining lymph nodes (160) showed that although a significant fraction of DCs expressed detectable levels of IDO protein by immunohistochemistry, the functional IDO-mediated suppression was mediated almost entirely by a small, well-defined CD19 ${ }^{+}$ subset among the B220 $0^{+}$plasmacytoid DCs. Furthermore, in humans an $\mathrm{IDO}^{+} \mathrm{DC}$ subset could be detected, which also expressed CD123 and CCR6 (29). Whether this particular DC phenotype is a specialized feature of tumor-draining lymph nodes or is a more general phenomenon remains to be elucidated, but this data emphasized that the biologically relevant population of IDO-expressing DCs might be a minor subset. Even within the population of IDO-competent DCs there can be a considerable degree of functional plasticity. Certain proinflammatory signals might down-regulate the expression of IDO by cells that would normally express it (96). In contrast, different tolerogenic stimuli might induce IDO expression by different DC populations $(96,163)$.

\subsection{Other regulatory DCs}

A number of reports described several populations of regulatory DCs. These cells were generated in response to different stromal cell and/or different cytokines. These cells most likely represent not a defined DC subset but rather cells that were "conditioned" by microenvironment to acquire certain features that make them immunosuppressive. It is possible, although no definitive data is yet available, that immunosuppressive features could be quite transitory and depend on the presence of those factors. These findings were made not in tumor models. However, it is likely that regulatory DCs could be found in tumor-bearing hosts and could play some role in tumor-associated immune suppression.

It has been reported that freshly isolated splenic stromal cells induced proliferation and differentiation of regulatory DC. This proliferation was dependent on cell-cell contact and fibronectin, while differentiation was dependent on cell-cell contact and TGF- $\beta$. Compared with fully matured DCs, these regulatory DCs had lower expression of MHC-II, CD86 and CD11c, but a higher expression of co-stimulatory molecules such as CD80, CD40, CD106 and CD11b. They also secreted more IL-10 and nitric oxide and less IL-12 and TGF- $\beta$. These cells strongly inhibited the proliferative response of naive $\mathrm{CD} 4^{+} \mathrm{T}$-cells to antigen presented by mature DCs. The inhibitory effects of regulatory DCs on T-cell proliferation were mediated by nitric oxide and did not involve differentiation of $\mathrm{CD} 4^{+} \mathrm{T}$-cells into regulatory $\mathrm{T}$-cells 
(164). IL-10-treated iDCs (165) and 1 $\alpha, 25$-dihydroxyvitamin $\mathrm{D}_{3}$-treated iDCs (166) have been reported to induce anergic $\mathrm{CD} 4^{+} \mathrm{T}$-cells in vitro. These regulatory DCs exhibited moderately high levels of MHC molecules, whereas they exhibited little expression of co-stimulatory molecules as compared with their normal counterparts. Furthermore, culture of bone marrow cells in the presence of IL-10 induces the differentiation of a distinct subset of dendritic cells with a specific expression of CD45RB. These CD11 $\mathrm{c}^{\text {low }} \mathrm{CD} 45 \mathrm{RB}{ }^{\text {high }} \mathrm{DCs}$ are present in the spleen and lymph nodes of normal mice and are significantly enriched in the spleen of IL-10 transgenic mice (167). These natural or in vitro-derived DCs display plasmacytoid morphology and an immature-like phenotype, and secrete high levels of IL-10 after activation (167).

\subsection{Immature myeloid cells in cancer}

IMCs are a heterogeneous population of myeloid cells comprised of immature macrophages, granulocytes, DCs and other myeloid cells at early stages of differentiation. In mice, IMCs are defined as $\mathrm{Gr}-1^{+} \mathrm{CD} 11 \mathrm{~b}^{+}$cells (168). IMCs are present in the bone marrow and spleen of healthy mice and differentiate into mature myeloid cells - granulocytes, macrophages and DCs - in vitro in the presence of GM-CSF or in vivo after adoptive transfer into naïve healthy recipients (169). However, they accumulate in the spleen and, to some extent, in the lymph nodes of mice bearing many different tumors (170-174). In tumor-bearing mice, these IMCs express MHC-I molecules but lack expression of MHC-II and costimulatory molecules. The functional activity of IMCs involves the inhibition of IFN $-\gamma$ production by $\mathrm{CD} 8^{+} \mathrm{T}$ cells in response to peptide epitopes presented by MHC-I molecules on the surface of IMCs in vitro and in vivo (173). This effect depends on MHC-I expression by IMCs, is not mediated by soluble factors, requires direct cell-cell contact and is mediated by reactive oxygen species, such as hydrogen peroxide $\left(\mathrm{H}_{2} \mathrm{O}_{2}\right)(175)$. Recent studies in vivo have demonstrated that IMC can induce antigen-specific $\mathrm{T}$ cell tolerance (176). By adoptive transfer of transgenic T-cells into naive recipients, Kusmartsev et al. have found that the population of IMC from tumorbearing mice was able to induce $\mathrm{CD} 8^{+} \mathrm{T}$-cell tolerance (176). Neither IMC from control mice nor progeny of tumor-derived IMC, including tumor-derived CD11 $\mathrm{c}^{+} \mathrm{DCs}$ were able to render $\mathrm{T}$ cells nonresponsive. IMC were able to take up soluble protein in vivo, process it, present antigenic epitopes on their surface and induce antigen-specific T-cell anergy (176). The subset of IMC, Gr- $1^{+} \mathrm{CD} 115^{+}$cells in addition to being able to suppress T-cell proliferation in vitro, could induce the development of Foxp $3^{+} \mathrm{T}$ regs in vivo (177). The development of Tregs required antigen-associated activation of tumor-specific T-cells, was dependent on the presence of IFN- $\gamma$ and IL-10, and was independent of nitric oxide (177). Interestingly, freshly isolated IMCs were not able to suppress $\mathrm{CD}^{+} \mathrm{T}$-cells, whereas when IMCs were incubated for several days in vitro they acquired the ability to eliminate CD4-mediated T-cell responses through induction of apoptosis (178). Gr- $1^{+} \mathrm{IMCs}$ differentiate in vitro into $\mathrm{F} 4 / 80^{+}$ macrophages. These macrophages produce high levels of nitric oxide and can directly induce T-cell apoptosis (179). After adoptive transfer to tumor-bearing recipients, IMC freshly isolated from spleens of tumor-bearing mice become F4/80+ tumor-associated macrophages (TAM). These TAM, but not $\mathrm{F} 4 / 80^{+}$macrophages or $\mathrm{Gr}-1^{+} \mathrm{IMCs}$ freshly isolated from spleens of tumor-bearing or naive mice were able to inhibit T-cell-mediated immune response in vitro via induction of T-cell apoptosis. Arginase and nitric oxide were both responsible for the apoptotic mechanism, and were seen only in TAM, but not in freshly isolated IMC. It appears that STAT1, but not STAT3 or STAT6, was responsible for TAM-suppressive activity (179).

In humans, IMCs are defined as cells that express the common myeloid marker CD33, but lack expression of markers of mature myeloid and lymphoid cells and the MHC-II molecule HLADR (180). An accumulation of IMCs was associated with the decreased numbers of DCs in the peripheral blood of patients with head and neck, lung, and breast cancer (147). Advanced-stage cancer promoted the accumulation of these cells in blood, whereas surgical resection of the tumor decreased the number of immature cells. A similar effect of tumor resection was 
observed in mouse tumor models (181). To investigate whether IMCs obtained from patients with cancer affect MHC-I-restricted T-cell responses, HLA-A2 ${ }^{+}$T-cells specific for an influenza virus-derived peptide were incubated with IMCs isolated from the peripheral blood of HLA-A2-positive patients with cancer (180). These IMCs inhibited the production of IFN$\gamma$ by autologous CD8 ${ }^{+} T$ cells stimulated by peptide-pulsed DCs. Schmielau and Finn (182) observed that in blood samples from patients with cancer, an unusually large number of myeloid cells with granulocyte phenotype co-purified with low-density peripheral blood mononuclear cells. Freshly isolated granulocytes from healthy donors, if activated, can also inhibit cytokine production by T-cells. This action is abrogated by addition of the hydrogen peroxide scavenger, catalase, implicating $\mathrm{H}_{2} \mathrm{O}_{2}$ as the effector molecule. These results are consistent with our findings for mouse IMCs, where hyper-production of $\mathrm{H}_{2} \mathrm{O}_{2}$ was found to be responsible for IMC-induced T-cell suppression $(169,175)$.

Thus, tumors employ rather elaborate strategies to subvert APC functions (183). A multitude of tumor-derived factors affect normal processes of myeloid cell differentiation, which results in block of differentiation of mature DCs and accumulation of iDC and pDC. These cells are not able to effectively stimulate immune response and instead can induce T-cell tolerance due to inability to present antigens in the context of co-stimulatory molecules. Tumor microenvironment can also affect iDC converting them to immunosuppressive regulatory cells. These cells may induce T-cell defects via various mechanisms including IDO-mediated tryptophan depletion and production of IL-10. In addition, tumor-derived factors stimulate hyper-production of immature myeloid suppressor cells that probably via hyper-production of reactive oxygen species and direct cell-cell contact induce antigen-specific T-cell tolerance. It is important to point out that most of the available data was obtained in experimental systems in vitro. Their biological role in suppression of immune response in cancer remained to be elucidated. It is possible that all of these factors are important in preventing the immune system to respond to tumor-specific antigen. The current status of the field will allow investigators to test all these possibilities. This is important not only for our better understanding of the biology of the immune reactivity in cancer but also for the development of the most effective therapeutic strategies.

\section{Conclusions and Future Directions}

Current attempts at harnessing the immune system to eliminate tumors focus on vaccination to increase the frequency of tumor-specific CTLs and adoptive transfer of effector T-cells to promote tumor regression $(184,185)$. However, despite considerable success in pre-clinical studies, the outcome of immunotherapy is often disappointing when translated to clinical trials. It has been proposed that the tumor microenvironment can restrict the effectiveness of antitumor responses by displaying a variety of immunosuppressive strategies. Yet, in spite of an improved understanding of tumor-immune system interactions, there are still more questions than answers regarding the interactions and hierarchy of the different tolerance mechanisms and their impact in cancer immunotherapy. Quantitative and dynamic models will be essential to dissect the kinetics of the interactions between different inhibitory molecules and the differentiation, expansion and trafficking of regulatory T-cells, NKT cells and DCs within tumor-draining lymph nodes and the tumor microenvironment. In addition it will be critical to determine the effectiveness of combined strategies involving blockade of different inhibitory signals (PD-1/PD-L1, IDO, TGF- $\beta$, IL-10, VEGF, FasL, galectin-1) together with conventional chemotherapy, vaccination or adoptive transfer of effector CTLs. Progress has been made in this direction by evaluating the effects of combined strategies, such as GM-CSF-secreting vaccines plus CTLA-4 blockade, chemotherapy plus IDO blockade and GM-CSF-secreting vaccines plus OX-40 signaling $(39,42,43,48,99,186)$. The current wealth of available data provides an unprecedented opportunity to successfully translate novel basic knowledge from "the bench to the bedside", promising a future scenario in which removal of inhibitory signals 
in the tumor microenvironment will be successful in combination with other therapeutic strategies to overcome immunological tolerance.

\section{Acknowledgments}

We give special thanks to members of authors' laboratories, in particular to Marta Toscano and Juan Ilarregui for their invaluable help in the illustration and discussion of this review. We apologize that we could not cite many excellent studies because of space limitations. Work in the authors laboratories is supported by grants from Cancer Research Institute (USA) Mizutani Foundation for Glycoscience (Japan), Agencia de Promoción Científica y Tecnológica (PICT 2003-05-13787), Fundación Sales (Argentina), Fundación Florencio Fiorini (Argentina) and University of Buenos Aires (M091, Argentina) to G.A.R.. G.A.R. is a member of the scientific career of the National Research Council (CONICET, Argentina).

\section{Literature Cited}

1. Smyth MJ, Godfrey DI, Trapani JA. A fresh look at tumor immunosurveillance and immunotherapy. Nat Immunol 2001;2:293-299. [PubMed: 11276199]

2. Drake CG, Jaffee E, Pardoll DM. Mechanisms of immune evasion by tumors. Adv Immunol 2006;90:51-81. [PubMed: 16730261]

3. Dunn GP, Old LJ, Schreiber RD. The three Es of cancer immunoediting. Annu Rev Immunol 2004;22:329-360. [PubMed: 15032581]

4. Shankaran V, Ikeda H, Bruce AT, White JM, Swanson PE, Old LJ, Schreiber RD. IFN- $\gamma$ and lymphocytes prevent primary tumor development and shape tumor immunogenicity. Nature 2001;410:1107-1111. [PubMed: 11323675]

5. Boon T, Coulie PG, Van den Eynde BJ, Van der Bruggen P. Human T-cell responses against melanoma. Annu Rev Immunol 2006;24:175-208. [PubMed: 16551247]

6. Rosenberg SA. A new era for cancer immunotherapy based on the genes that encode cancer antigens. Immunity 1999;10:281-287. [PubMed: 10204484]

7. Sotomayor EM, Borrello I, Levitsky HI. Tolerance and cancer: a critical issue in tumor immunology. Crit Rev Oncog 1996;7:433-456. [PubMed: 9467666]

8. Bogen B. Peripheral T cell tolerance as a tumor escape mechanism: deletion of CD4+ T cells specific for a monoclonal immunoglobulin idiotype secreted by a plasmacytoma. Eur J Immunol 1996;26:2671-2679. [PubMed: 8921954]

9. Staveley, O'Carroll K.; Sotomayor, E.; Montgomery, J.; Borrello, I.; Hwang, L.; Fein, S.; Pardoll, D.; Levitsky, H. Induction of antigen-specific T cell anergy: An early event in the course of tumor progression. Proc Natl Acad Sci USA 1998;95:1178-1183. [PubMed: 9448305]

10. Cuenca A, Cheng F, Wang H, Brayer J, Horna P, Gu L, Bien H, Borrello IM, Levitsky HI, Sotomayor EM. Extra-lymphatic solid tumor growth is not immunologically ignored and results in early induction of antigen-specific T-cell anergy: dominant role of cross-tolerance to tumor antigens. Cancer Res 2003;63:9007-9015. [PubMed: 14695219]

11. Morgan DJ, Kreuwel HT, Fleck S, Levitsky HI, Pardoll DM, Sherman LA. Activation of low avidity CTL specific for a self epitope results in tumor rejection but not autoimmunity. J Immunol 1998;160:643-651. [PubMed: 9551898]

12. Overwijk WW, Theoret MR, Finkelstein SE, Surman DR, de Jong LA, Vyth-Dreese FA, Dellemijn TA, Antony PA, Spiess PJ, Palmer DC, Heimann DM, Klebanoff CA, Yu Z, Hwang LN, Feigenbaum L, Kruisbeek AM, Rosenberg SA, Restifo NP. Tumor regression and autoimmunity after reversal of a functionally tolerant state of self-reactive CD8+ T cells. J Exp Med 2003;198:569-580. [PubMed: 12925674]

13. Willimsky G, Blankenstein T. Sporadic immunogenic tumours avoid destruction by inducing T-cell tolerance. Nature 2005;437:141-146. [PubMed: 16136144]

14. Lee PP, Yee C, Savage PA, Fong L, Brockstedt D, Weber JS, Johnson D, Swetter S, Thompson J, Greenberg PD, Roederer M, Davis MM. Characterization of circulating T cells specific for tumorassociated antigens in melanoma patients. Nat Med 1999;5:677-685. [PubMed: 10371507] 
15. Noonan K, Matsui W, Serafini P, Carbley R, Tan G, Khalili J, Bonyhadi M, Levitsky H, Whartenby K, Borrello I. Activated marrow-infiltrating lymphocytes effectively target plasma cells and their clonogenic precursors. Cancer Res 2005;65:2026-2034. [PubMed: 15753403]

16. Pardoll D. Does the immune system see tumors as foreign or self? Annu Rev Immunol 2003;21:807839. [PubMed: 12615893]

17. Horna P, Cuenca A, Cheng F, Brayer J, Wang HW, Borrello I, Levitsky H, Sotomayor EM. In vivo disruption of tolerogenic cross-presentation mechanisms uncovers an effective T-cell activation by B-cell lymphomas leading to antitumor immunity. Blood 2006;107:2871-2878. [PubMed: 16339406]

18. Drake CG, Doody AD, Mihalyo MA, Huang CT, Kelleher E, Ravi S, Hipkiss EL, Flies DB, Kennedy EP, Long M, McGary PW, Coryell L, Nelson WG, Pardoll DM, Adler AJ. Androgen ablation mitigates tolerance to a prostate/prostate cancer-restricted antigen. Cancer Cell 2005;7:239-249. [PubMed: 15766662]

19. Zhou G, Drake CG, Levitsky HI. Amplification of tumor-specific regulatory T cells following therapeutic cancer vaccines. Blood 2006;107:628-636. [PubMed: 16179369]

20. Ochsenbein AF, Klenerman P, Karrer U, Ludewig B, Pericin M, Hengartner H, Zinkernagel RM. Immune surveillance against a solid tumor fails because of immunological ignorance. Proc Natl Acad Sci U S A 1999;96:2233-2238. [PubMed: 10051624]

21. Dalyot-Herman N, Bathe OF, Malek TR. Reversal of CD8+ T cell ignorance and induction of antitumor immunity by peptide-pulsed APC. J Immunol 2000;165:6731-6737. [PubMed: 11120791]

22. Ohlen C, Kalos M, Hong DJ, Shur AC, Greenberg PD. Expression of a tolerizing tumor antigen in peripheral tissue does not preclude recovery of high-affinity CD8+ T cells or CTL immunotherapy of tumors expressing the antigen. J Immunol 2001;166:2863-2870. [PubMed: 11160355]

23. Lyman MA, Aung S, Biggs JA, Sherman LA. A spontaneously arising pancreatic tumor does not promote the differentiation of naive CD8+ T lymphocytes into effector CTL. J Immunol 2004;172:6558-6567. [PubMed: 15153470]

24. Otten GR, Germain RN. Split anergy in a CD8+ T cell: receptor-dependent cytolysis in the absence of interleukin-2 production. Science 1991;251:1228-1231. [PubMed: 1900952]

25. Vezys V, Olson S, Lefrancois L. Expression of intestine-specific antigen reveals novel pathways of CD8+ T cell tolerance induction. Immunity 2000;12:505-514. [PubMed: 10843383]

26. Sotomayor EM, Borrello I, Rattis FM, Cuenca AG, Abrams J, Staveley O'Carroll K, Levitsky HI. Cross-presentation of tumor antigens by bone marrow-derived antigen-presenting cells is the dominant mechanism in the induction of T-cell tolerance during B-cell lymphoma progression. Blood 2001;98:1070-1077. [PubMed: 11493453]

27. Steinman RM, Hawiger D, Nussenzweig MC. Tolerogenic dendritic cells. Annu Rev Immunol 2003;21:685-711. [PubMed: 12615891]

28. Belz GT, Behrens GM, Smith CM, Miller JF, Jones C, Lejon K, Fathman CG, Mueller SN, Shortman $\mathrm{K}$, Carbone FR, Heath WR. The CD8alpha(+) dendritic cell is responsible for inducing peripheral self-tolerance to tissue-associated antigens. J Exp Med 2002;196:1099-1104. [PubMed: 12391021]

29. Munn DH, Sharma MD, Lee JR, Jhaver KG, Johnson TS, Keskin DB, Marshall B, Chandler P, Antonia SJ, Burgess R, Slingluff CL Jr, Mellor AL. Potential regulatory function of human dendritic cells expressing indoleamine 2,3-dioxygenase. Science 2002;297:1867-1870. [PubMed: 12228717]

30. Fuchs EJ, Matzinger P. Is cancer dangerous to the immune system? Semin Immunol 1996;8:271280. [PubMed: 8956455]

31. Gerlini G, Tun-Kyi A, Dudli C, Burg G, Pimpinelli N, Nestle FO. Metastatic melanoma secreted IL-10 down-regulates CD1 molecules on dendritic cells in metastatic tumor lesions. Am J Pathol 2004;165:1853-1863. [PubMed: 15579430]

32. Gabrilovich DI, Chen HL, Girgis KR, Cunningham HT, Meny GM, Nadaf S, Kavanaugh D, Carbone DP. Production of vascular endothelial growth factor by human tumors inhibits the functional maturation of dendritic cells. Nat Med 1996;2:1096-1103. [PubMed: 8837607]

33. Wang T, Niu G, Kortylewski M, Burdelya L, Shain K, Zhang S, Bhattacharya R, Gabrilovich D, Heller R, Coppola D, Dalton W, Jove R, Pardoll D, Yu H. Regulation of the innate and adaptive immune responses by Stat-3 signaling in tumor cells. Nat Med 2004;10:48-54. [PubMed: 14702634] 
34. Cheng F, Wang HW, Cuenca A, Huang M, Ghansah T, Brayer J, Kerr WG, Takeda K, Akira S, Schoenberger SP, Yu H, Jove R, Sotomayor EM. A critical role for Stat3 signaling in immune tolerance. Immunity 2003;19:425-436. [PubMed: 14499117]

35. Welte T, Zhang SS, Wang T, Zhang Z, Hesslein DG, Yin Z, Kano A, Iwamoto Y, Li E, Craft JE, Bothwell AL, Fikrig E, Koni PA, Flavell RA, Fu XY. STAT3 deletion during hematopoiesis causes Crohn's disease-like pathogenesis and lethality: a critical role of STAT3 in innate immunity. Proc Natl Acad Sci USA 2003;100:1879-1884. [PubMed: 12571365]

36. Evel-Kabler K, Song XT, Aldrich M, Huang XF, Chen SY. SOCS1 restricts dendritic cells' ability to break self tolerance and induce antitumor immunity by regulating IL-12 production and signaling. $\mathrm{J}$ Clin Invest 2006;116:90-100. [PubMed: 16357940]

37. Kawakami Y, Inagaki N, Salek-Ardakani S, Kitaura J, Tanaka H, Nagao K, Xiao W, Nagai H, Croft M, Kawakami T. Regulation of dendritic cell maturation and function by Bruton's tyrosine kinase via IL-10 and Stat3. Proc Natl Acad Sci U S A 2006;103:153-158. [PubMed: 16371463]

38. Wang H, Cheng F, Cuenca A, Horna P, Zheng Z, Bhalla K, Sotomayor EM. Imatinib mesylate (STI-571) enhances antigen-presenting cell function and overcomes tumor-induced CD4+ T-cell tolerance. Blood 2005;105:1135-1143. [PubMed: 15454486]

39. Korman AJ, Peggs KS, Allison JP. Checkpoint blockade in cancer immunotherapy. Adv Immunol 2006;90:297-339. [PubMed: 16730267]

40. Perez VL, Van Parijs L, Biuckians A, Zheng XX, Strom TB, Abbas AK. Induction of peripheral T cell tolerance in vivo requires CTLA-4 engagement. Immunity 1997;6:411-417. [PubMed: 9133420]

41. Sotomayor EM, Borrello I, Tubb E, Allison JP, Levitsky HI. In vivo blockade of CTLA-4 enhances the priming of responsive T cells but fails to prevent the induction of tumor antigen-specific tolerance. Proc Natl Acad Sci U S A 1999;96:11476-11481. [PubMed: 10500201]

42. van Elsas A, Hurwitz AA, Allison JP. Combination immunotherapy of B16 melanoma using anticytotoxic T lymphocyte-associated antigen 4 (CTLA-4) and granulocyte/macrophage colonystimulating factor (GM-CSF)-producing vaccines induces rejection of subcutaneous and metastatic tumors accompanied by autoimmune depigmentation. J Exp Med 1999;190:355-366. [PubMed: 10430624]

43. Phan GQ, Yang JC, Sherry RM, Hwu P, Topalian SL, Schwartzentruber DJ, Restifo NP, Haworth LR, Seipp CA, Freezer LJ, Morton KE, Mavroukakis SA, Duray PH, Steinberg SM, Allison JP, Davis TA, Rosenberg SA. Cancer regression and autoimmunity induced by cytotoxic T lymphocyteassociated antigen 4 blockade in patients with metastatic melanoma. Proc Natl Acad Sci U S A 2003;100:8372-8377. [PubMed: 12826605]

44. Daniels GA, Sanchez-Perez L, Diaz RM, Kottke T, Thompson J, Lai M, Gough M, Karim M, Bushell A, Chong H, Melcher A, Harrington K, Vile RG. A simple method to cure established tumors by inflammatory killing of normal cells. Nat Biotechnol 2004;22:1125-1132. [PubMed: 15300260]

45. Sotomayor EM, Borrello I, Tubb E, Rattis FM, Bien H, Lu Z, Fein S, Schoenberger S, Levitsky HI. Conversion of tumor-specific CD4+ T-cell tolerance to T-cell priming through in vivo ligation of CD40. Nat Med 1999;5:780-787. [PubMed: 10395323]

46. Diehl L, den Boer AT, Schoenberger SP, van der Voort EI, Schumacher TN, Melief CJ, Offringa R, Toes RE. CD40 activation in vivo overcomes peptide-induced peripheral cytotoxic T-lymphocyte tolerance and augments anti-tumor vaccine efficacy. Nat Med 1999;5:774-779. [PubMed: 10395322]

47. Bansal-Pakala P, Jember AG, Croft M. Signaling through OX40 (CD134) breaks peripheral T-cell tolerance. Nat Med 2001;7:907-912. [PubMed: 11479622]

48. Murata S, Ladle BH, Kim PS, Lutz ER, Wolpoe ME, Ivie SE, Smith HM, Armstrong TD, Emens LA, Jaffee EM, Reilly RT. OX40 costimulation synergizes with GM-CSF whole-cell vaccination to overcome established CD8+ T cell tolerance to an endogenous tumor antigen. J Immunol 2006;176:974-983. [PubMed: 16393983]

49. Teague RM, Sather BD, Sacks JA, Huang MZ, Dossett ML, Morimoto J, Tan X, Sutton SE, Cooke MP, Ohlen C, Greenberg PD. Interleukin-15 rescues tolerant CD8+ T cells for use in adoptive immunotherapy of established tumors. Nat Med 2006;12:335-341. [PubMed: 16474399]

50. Igney FH, Krammer PH. Immune escape of tumors: apoptosis resistance and tumor counterattack. J Leukoc Biol 2002;71:907-920. [PubMed: 12050175] 
51. Whiteside TL. Immune suppression in cancer: Effects on immune cells, mechanisms and future therapeutic intervention. Sem Cancer Biol 2006;16:3-15.

52. Khong HT, Restifo NP. Natural selection of tumor variants in the generation of "tumor escape" phenotypes. Nat Immunol 2002;3:999-1005. [PubMed: 12407407]

53. Blank C, Gajewski T, Mackensen A. Interaction of PD-L1 on tumor cells with PD-1 on tumor-specific $\mathrm{T}$ cells as a mechanism of immune evasion: implications for tumor immunotherapy. Cancer Immunol Immunother 2005;54:307-314. [PubMed: 15599732]

54. Pardoll D, Allison J. Cancer immunotherapy: breaking the barriers to harvest the crop. Nat Med 2004;9:887-892. [PubMed: 15340404]

55. Marincola FM, Jaffee EM, Hicklin DJ, Ferrone S. Escape of human solid tumors from T-cell recognition: molecular mechanisms and significance. Adv Immunol 2000;74:181-273. [PubMed: 10605607]

56. Spiotto MT, Rowley DA, Schreiber H. Bystander elimination of antigen loss variants in established tumors. Nat Med 2004;10:294-298. [PubMed: 14981514]

57. Rivoltini L, Carrabba M, Huber V, Castelli C, Novellino L, Dalerba P, Mortarini R, Arancia G, Anichini A, Fais S, Parmiani G. Immunity to cancer: attack and escape in T lymphocyte-tumor cell interaction. Immunol Rev 2002;188:97-113. [PubMed: 12445284]

58. Hicklin DJ, Marincola FM, Ferrone S. HLA class I antigen downregulation in human cancers: T-cell immunotherapy revives and old story. Mol Med Today 1999;5:178-186. [PubMed: 10203751]

59. Bicknell DC, Rowan A, Bodmer WF. Beta 2-microglobulin gene mutations: a study of established colorectal cell lines and fresh tumors. Proc Natl Acad Sci USA 1994;91:4751-4756. [PubMed: 8197130]

60. Wang Z, Cao Y, Albino AP, Zeff RA, Houghton A, Ferrone S. Lack of HLA class I antigen expression by melanoma cells SK-MEL-33 caused by a reading frameshift in beta 2-microglobulin messanger RNA. J Clin Invest 1993;91:684-692. [PubMed: 8432869]

61. Natali PG, Nicotra MR, Bigotti A, Venturo L, Marcenaro L, Giacomini P, Russo C. Selective changes in expression of HLA class I polymorphic determinants in human solid tumors. Proc Natl Acad Sci USA 1989;86:6719-6723. [PubMed: 2672003]

62. Lanier LL. NK cell recognition. Annu Rev Immunol 2005;23:225-274. [PubMed: 15771571]

63. Groh V, Wu J, Yee C, Spies T. Tumor-derived soluble MIC ligands impair expression of NKG2D and T-cell activation. Nature 2002;419:734-738. [PubMed: 12384702]

64. Jinushi M, Hodi FS, Dranoff G. Therapy-induced antibodies against MHC class I chain-realted protein A antagonize immune suppression and stimule antitumor cytotoxicity. Proc Natl Acad Sci USA 2006;103:9190-9195. [PubMed: 16754847]

65. Mizoguchi H, O’Shea JJ, Longo D, Loeffler CM, McVicar DW, Ochoa AC. Alternations in signal transduction molecules in T lymphocytes from tumor-bearing mice. Science 1992;258:1795-1798. [PubMed: 1465616]

66. Koneru M, Schaer D, Monu N, Ayala A, Frey AB. Defective proximal TCR signaling inhibits CD8 + tumor-infiltrating lymphocyte lytic function. J Immunol 2005;174:1830-1840. [PubMed: 15699109]

67. Waldmann TA. Effective cancer therapy through immunomodulation. Annu Rev Med 2006;57:6581. [PubMed: 16409137]

68. Li MO, Wang YY, Sanjabi S, Robertson AK, Flavell RA. Transforming growth factor- $\beta$ regulation of immune responses. Annu Rev Immunol 2006;24:99-146. [PubMed: 16551245]

69. Torre-Amione G, Beauchamp RD, Koeppen H, Park BH, Schreiber H, Moses HL, Rowley DA. A highly immunogenic tumor transfected with a murine transforming growth factor type beta $1 \mathrm{cDNA}$ escapes immune surveillance. Proc Natl Acad Sci USA 1990;87:1486-1490. [PubMed: 2137615]

70. Gorelik L, Flavell RD. Immune-mediated eradication of tumors through the blockade of transforming growth factor- $\beta$ signaling in T cells. Nat Med 2001;7:1118-1122. [PubMed: 11590434]

71. Thomas DA, Massague J. TGF- $\beta$ directly targets cytotoxic T cell functions during tumor evasion of immune surveillance. Cancer Cell 2005;8:369-380. [PubMed: 16286245]

72. Ahmadzadeh M, Rosenberg SA. TGF- $\beta 1$ attenuates the acquisition and expression of effector function by tumor antigen-specific human memory CD8 T cells. J Immunol 2005;174:5215-5223. [PubMed: 15843517] 
73. Terabe M, Matsui S, Noben-Trauth N, Chen H, Watson C, Donaldson DD, Carbone DP, Paul WE, Berzofsky JA. NKT cell-mediated repression of tumor immunosurveillance by IL-13 and the IL-4RSTAT6 pathway. Nat Immunol 2000;1:515-520. [PubMed: 11101874]

74. Kaklamani V, Pasche B. Role of TGF- $\beta$ in cancer and the potential for therapy and prevention. Expert Rev Anticancer Ther 2004;4:649-661. [PubMed: 15270668]

75. Kurte M, Lopez M, Aguirre A, Escobar A, Aguillon JC, Charo J, Larsen CG, Kiessling R, SalazarOnfray F. A synthetic peptide homologous to functional domain of human IL-10 down-regulates expression of MHC class I and transporter associated with antigen processing 1/2 in human melanoma cells. J Immunol 2004;173:1731-1737. [PubMed: 15265902]

76. Akasaki Y, Liu G, Chung NH, Ehtesham M, Black KL, Yu JS. Induction of a CD4+ T regulatory type 1 response by cyclooxigenase-2-overexpressing gliomas. J Immunol 2004;173:4352-4359. [PubMed: 15383564]

77. Agrawal B, Krantz MJ, Reddish MA, Longenecker BM. Cancer-associated MUC1 mucin inhibits human T-cell proliferation, which is reversible by IL-2. Nat Med 1998;4:43-49. [PubMed: 9427605]

78. Mocellin S, Marincola FM, Young HA. Interleukin-10 and the immune response against cancer: a counterpoint. J Leukoc Biol 2005;78:1043-1051. [PubMed: 16204623]

79. Lopez MV, Adris SK, Bravo AI, Chernajovsky Y, Podhajcer OL. IL-12 and IL-10 expression synergize to induce immune-mediated eradication of established colon and mammary tumors and lung metastasis. J Immunol 2005;175:5885-5894. [PubMed: 16237081]

80. Karim M, Greten FR. NF-kappaB: Linking inflammation and immunity to cancer development and progression. Nat Rev Immunol 2005;5:749-759. [PubMed: 16175180]

81. Luo JL, Maeda S, Hsu LC, Yagita H, Karin M. Inhibition of NF- $\kappa B$ in cancer cells converts inflammation-induced tumor growth mediated by TNF- $\alpha$ to TRAIL-mediated tumor regression. Cancer Cell 2004;6:297-305. [PubMed: 15380520]

82. Leach DR, Krummel MF, Allison JP. Enhancement of antitumor immunity by CTLA-4 blockade. Science 1996;271:1734-1736. [PubMed: 8596936]

83. Hodi FS, Mihm MC, Soiffer RJ, Haluska FG, Butler M, Seiden MV, Davis T, Henry-Spires R, MacRae S, Willman A, Padera R, Jaklitsch MT, Shankar S, Chen TC, Korman A, Allison JP, Dranoff G. Biologic activity of cytotoxic T lymphocyte-associated antigen 4 antibody blockade in previously vaccinated metastatic melanoma and ovarian carcinoma patients. Proc Natl Acad Sci USA 2003;100:4712-4717. [PubMed: 12682289]

84. Quezada SA, Peggs KS, Curran MA, Allison JP. CTLA4 blockade and GM-CSF combination immunotherapy alters the intratumor balance of effector and regulatory $\mathrm{T}$ cells. J Clin Invest 2006;116:1935-1945. [PubMed: 16778987]

85. Ishida Y, Agata Y, Shibahara K, Honjo T. Induced expression of PD-1, a novel member of the immunoglobulin gene superfamily, upon programmed cell death. EMBO J 1992;11:3887-3895. [PubMed: 1396582]

86. Nishimura H, Nose M, Hiai H, Minato N, Honjo T. Development of lupus-like autoimmune diseases by disruption of the PD-1 gene encoding an ITIM motif-carrying immunoreceptor. Immunity 1999;11:141-151. [PubMed: 10485649]

87. Freeman GJ, Long AJ, Iwai Y, Bourque K, Chernova T, NIshimura H, Fitz LJ, Malenkovich N, Okazaki T, Byrne MC, Horton HF, et al. Engagement of the PD-1 immunoinhibitory receptor by a novel B7 family member leads to negative regulation of lymphocyte activation. J Exp Med 2000;192:1027-1034. [PubMed: 11015443]

88. Dong H, Strome SE, Salomao DR, Tamura H, Hirano F, Files DB, Roche PC, Lu J, Zhu G, Tamada $\mathrm{K}$, Lennon VA. Tumor-associated B7-H1 promotes T-cell apoptosis: A potential mechanism of immune evasion. Nat Med 2002;8:793-800. [PubMed: 12091876]

89. Iwai Y, Ishida M, Tanaka Y, Okazaki T, Honjo T, Minato M. Involvement of PD-L1 on tumor cells in the escape from host immune system and tumor immunotherapy by PD-L1 blockade. Proc. Natl Acad Sci USA 2002;99:12293-12297. [PubMed: 12218188]

90. Blank C, Brown I, Peterson AC, Spiotto M, Iwai Y, Honjo T, Gajewski TF. PD-L1/B7-H1 inhibits the effector phase of tumor rejection by T-cell receptor (TCR) transgenic CD8+ T cells. Cancer Res 2004;64:1140-1145. [PubMed: 14871849] 
91. Curiel TJ, Wei S, Dong H, Alvarez X, Cheng P, Mottram P, Krzysiek R, Knutson K, Daniel B, Zimmermann MC, David O, Burow M, Gordon A, Dhurandhar N, Myers L, Berggren R, Hemminki A, Alvarez RD, Emilie D, Curiel DT, Cheng L, Zou W. Blockade of B7-H1 improves myeloid dendritic cell-mediated antitumor immunity. Nat Med 2003;9:562-567. [PubMed: 12704383]

92. Shin T, Yoshimura K, Shin T, Crafton EB, Tsuchiya H, Housseau F, Koseki H, Schulick RD, Cheng L, Pardoll DM. In vivo costimulatory role of B7-DC in tuning T helper cell 1 and cytotoxic T lymphocyte responses. J Exp Med 2005;201:1531-1541. [PubMed: 15897272]

93. Barber DL, Wherry EJ, Masopust D, Zhu B, Allison JP, Sharpe AH, Freeman GJ, Ahmed R. Restoring function in exhausted CD8 T cells during chronic viral infection. Nature 2006;439:669-670. [PubMed: 16467825]

94. Watanabe N, Gavrieli M, Sedy JR, Yang J, Fallarino F, Loftin SK, Hurchia MA, Zimmerman N, Sim J, Zang X, Murphy TL, Russel JH, Allison JP, Murphy KM. BTLA is a lymphocyte inhibitory receptor with similarities to CTLA-4 and PD-1. Nat Immunol 2003;4 679-79.

95. Kryczek I, Zou L, Rodriguez P, Zhu G, Wei S, Mottram P, Brumlik M, Cheng P, Curiel T, Myers L, Lackner A, Alvarez X, Ochoa A, Chen L, Zou W. B7-H4 expression identifies a novel suppressive macrophage population in human ovarian carcinoma. J Exp Med 2006;203:871-881. [PubMed: 16606666]

96. Mellor AL, Munn DH. Immunology at the maternal-fetal interface: lessons for T-cell tolerance and suppression. Annu Rev Immunol 2000;18:367-391. [PubMed: 10837063]

97. Munn DH, Zhou M, Attwood JT, Bondarev I, Conway SJ, Marshall BH, Brown C, Mellor AL. Prevention of allogeneic fetal rejection by tryptophan catabolism. Science 1998;281:1191-1193. [PubMed: 9712583]

98. Uyttenhove C, PIlotte L, Théate I, Stroobant V, Colau D, Parmentier N, Boon T, Van den Eynde BJ. Evidence for a tumoral immune resistance mechanism based on tryptophan degradation by indoleamine 2,3-dioxygenase. Nat Med 2003;9:1269-1274. [PubMed: 14502282]

99. Muller AJ, Duhadaway JB, Donover PS, Sutanto-Ward E, Prendergast GC. Inhibition of indoleamine 2,3-dioxygenase, an immunoregulatory target of the cancer suppression gene Bin1, potentiates cancer chemotherapy. Nat Med 2005;11:312-319. [PubMed: 15711557]

100. Siegel RM, Chan FK, Chun HJ, Lenardo MJ. The multifaceted role of Fas signaling in immune cell homeostasis and autoimmunity. Nat Immunol 2000;1:469-474. [PubMed: 11101867]

101. Green DR, Ferguson TA. The role of Fas ligand in immune privilege. Nat Rev Mol Cell Biol 2001;2:917-924. [PubMed: 11733771]

102. Hahne M, Rimoldi D, Schröter M, Romero P, French LE, Schneider P, Bornand T, Fontana A, Lienard D, Cerottini JC, Tschopp J. Melanoma cell expression of Fas (Apo-1/CD95) ligand: Implications for tumor-immune escape. Science 1996;274:1363-1366. [PubMed: 8910274]

103. O’Connel J, Houston A, Bennet MW, O’Sullivan GC, Shanahan F. Immune privilege or inflammation? Insights into the Fas ligand enigma. Nat Med 2001;7:271-274. [PubMed: 11231613]

104. Andreola G, Rivoltini L, Castelli C, Huber V, Perego P, Deho P, Squarcina P, Accornero P, Lozupone F, Lugini L, et al. Induction of lymphocyte apopotosis by tumor cell secretion of FasL-bearing microvesicles. J Exp Med 2002;195:1303-1316. [PubMed: 12021310]

105. Igney FH, Krammer PH. Tumor counterattack: fact or fiction? Cancer Immunol Immunother 2005;54:1127-1136. [PubMed: 15889255]

106. Chen JJ, Sun Y, Nabel GJ. Regulation of the proinflammatory effects of Fas ligand (CD95L). Science 1998;282:1714-1717. [PubMed: 9831564]

107. Chappell DB, Zaks TZ, Rosenberg SA, Restifo NP. Human melanoma cells do not express Fas (Apo-1/CD95) ligand. Cancer Res 1999;59:59-62. [PubMed: 9892185]

108. Ryan AE, Shanahan F, O’Connel J, Houston AM. Addressing the "Fas counterattack" controversy: blocking Fas ligand expression suppresses tumor immune evasion of colon cancer in vivo. Cancer Res 2005;65:9817-9823. [PubMed: 16267003]

109. Whiteside TL. Tumor-derived exosomes or microvesicles: another mechanism of tumor escape from the host immune system? Br J Cancer 2005;92:209-211. [PubMed: 15702078]

110. Lugini L, Matarrese P, Tinari A, Lozupone F, Federici C, Iessi E, Gentile M, Luciani F, Parmiani G, Rivoltini L, Malorni W, Fais S. Cannibalism of live lymphocytes by human metastatic but not primary melanoma cells. Cancer Res 2006;66:3629-3638. [PubMed: 16585188] 
111. Giovarelli M, Musiani P, Garotta G, Ebner R, Di Carlo E, Kim Y, Cappello P, Rigamonti L, Bernabei P, Novelli F, Modesti A, Coletti A, Ferrie AK, Lollini PL, Ruben S, Salcedo T, Forni AG. A "stealth effect": adenocarcinoma cells engineered to express TRAIL elude tumor-specific and allogeneic T cell reactions. J Immunol 1999;163:4886-4893. [PubMed: 10528190]

112. Mellado M, de Ana AM, Moreno MC, Martinez C, Rodríguez-Frade JM. A potential immune escape mechanism by melanoma cells through the activation of chemokine-induced T cell death. Curr Biol 2001;11:691-696. [PubMed: 11369232]

113. Nakashima M, Sonoda K, Watanabe T. Inhibition of cell growth and induction of apoptotic cell death by the human tumor-associated antigen RCAS1. Nat Med 1999;8:938-942. [PubMed: 10426319]

114. Chahlavi A, Rayman P, Richmond AL, Biswas K, Zhang R, Vogelbaum M, Tannenbaum C, Barnett G, Finke JH. Glioblastomas induce T-lymphocyte death by two distinct pathways involving gangliosides and CD70. Cancer Res 2005;65:5428-5438. [PubMed: 15958592]

115. Sakaguchi S. Naturally arising CD4+ regulatory T cells for immunologic self-tolerance and negative control of immune responses. Annu Rev Immunol 2004;22:531-562. [PubMed: 15032588]

116. Zou W. Immunosuppressive networks in the tumor microenvironment and their therapeutic relevance. Nat Rev Cancer 2005;5:263-274. [PubMed: 15776005]

117. Curiel TJ, Coukos G, Zou L, Alvarez X, Cheng P, Mottram P, Evdemon-Hogan M, Conejo-Garcia JR, Zhang L, Burow M, Zhu Y, Wei S, Kryczek I, Daniel B, Gordon A, Myers L, Lackner A, Disis ML, Knutson KL, Chen L, Zou W. Specific recruitment of regulatory T cells in ovarian carcinoma fosters immune privilege and predicts reduced survival. Nat Med 2004;10:942-949. [PubMed: 15322536]

118. Shimizu J, Yamazaki S, Sakaguchi S. Induction of tumor immunity by removing CD25+CD4+ T cells: a common basis between tumor immunity and autoimmunity. J Immunol 1999;163:52115218. [PubMed: 10553041]

119. Onizuka S, Tawara I, Shimizu J, Sakaguchi S, Fujita T, Nakayama E. Tumor rejection by in vivo administration of anti-CD25 (interleukin-2 receptor alpha) monoclonal antibody. Cancer Res 1999;59:3128-3133. [PubMed: 10397255]

120. Turk MJ, Guevara-Patino JA, Rizzuto GA, Engelhorn ME, Sakaguchi S, Houghton AN. Concomitant tumor immunity to a poorly immunogenic melanoma is prevented by regulatory $\mathrm{T}$ cells. J Exp Med 2004;200:771-782. [PubMed: 15381730]

121. Shevach EM, Stephens GL. The GITR-GITRL interaction: costimulation or contrasuppression of regulatory activity? Nat Rev Immunol 2006;6:613-618. [PubMed: 16868552]

122. Pasare C, Medzhitov R. Toll pathway-dependent blockade of CD4+CD25+ T cell-mediated suppression by dendritic cells. Science 2003;299:1033-1036. [PubMed: 12532024]

123. Peng G, Guo Z, Kiniwa Y, Voo KS, Peng W, Fu T, Wang DY, Li Y, Wang HY, Wang RF. Tolllike receptor-8-mediated reversal of CD4+ regulatory T cell function. Science 2005;309:13801384. [PubMed: 16123302]

124. Ercolini AM, Ladle BH, Manning EA, Pfannenstiel LW, Armstrong TD, Machiels JP, Bieler JG, Emens LA, Reilly RT, Jaffee EM. Recruitment of latent pools of high-avidity CD8+ T cells to the antitumor response. J Exp Med 2005;201:1591-1602. [PubMed: 15883172]

125. O’Garra A, Vieira PL, Viera P, Goldfeld AE. IL-10-producing and naturally occurring CD4+ Tregs: limiting collateral damage. J Clin Invest 2004;114:1372-1378. [PubMed: 15545984]

126. Taams LS, Palmer DB, Akbar AN, Robinson DS, Brown Z, Hawrylowicz CM. Regulatory T cells in human disease and their potential for therapeutic manipulation. Immunology 2006;118:1-9. [PubMed: 16630018]

127. Fiore F, Nuschak B, Peola S, Mariani S, Muraro M, Foglieta M, Coscia M, Bruno B, Boccadoro M, Massaia M. Exposure to myeloma cell lysates affects the immune competence of dendritic cells and favors the induction of Tr1-like regulatory T cells. Eur J Immunol 2005;35:1155-1163. [PubMed: 15761844]

128. Camby I, Mercier ML, Lefranc F, Kiss R. Galectin-1: a small protein with major functions. Glycobiology. 2006 [Epub ahead of print].

129. Liu FT, Rabinovich GA. Galectins as modulators of tumour progression. Nat Rev Cancer 2005;5:29_ 41. [PubMed: 15630413] 
130. Perillo NL, Pace KE, Seihamer JJ, Baum LG. Apoptosis of T cells mediated by galectin-1. Nature 1995;378:736-739. [PubMed: 7501023]

131. Matarrese P, Tinari A, Mormone E, Bianco GA, Toscano MA, Ascione B, Rabinovich GA, Malorni W. Galectin-1 sensitizes resting human T lymphocytes to Fas (CD95)-mediated cell death via mitochondrial hyperpolarization, budding and fission. J Biol Chem 2005;280:6969-6985. [PubMed: 15556941]

132. Chung CD, Patel VP, Moran M, Lewis LA, Micelli MC. Galectin-1 induces partial TCR $\zeta$-chain phosphorylation and antagonizes processive TCR signal transduction. J Immunol 2000;165:37223729. [PubMed: 11034377]

133. Rabinovich GA, Daly G, Dreja H, Tailor H, Riera CM, Hirabayashi J, Chernajovsky Y. Recombinant galectin-1 and its genetic delivery suppress collagen-induced arthritis via T cell apoptosis. J Exp Med 1999;190:385-397. [PubMed: 10430627]

134. Rabinovich GA, Baum LG, Tinari N, Paganelli R, Natoli C, Liu FT, Iacobelli S. Galectins and their ligands: amplifiers, silencers or tuners of the inflammatory response? Trends Immunol 2002;23:313-320. [PubMed: 12072371]

135. Rubinstein N, Alvarez M, Zwirner NW, Toscano MA, Ilarregui JM, Bravo A, Mordoh J, Fainboim L, Podhajcer OL, Rabinovich GA. Targeted inhibition of galectin-1 gene expression in tumor cells results in heightened T-cell mediated tumor rejection: A potential mechanism of tumor-immune privilege. Cancer Cell 2004;5:241-251. [PubMed: 15050916]

136. Sturm A, Lensch M, Andre S, Kaltner H, Wiedenmann B, Rosewicz S, Dignass AU, Gabius HJ. Human galectin-2: novel inducer of $\mathrm{T}$ cell apoptosis with distinct profile of caspase activation. $\mathrm{J}$ Immunol 2004;173:3825-3837. [PubMed: 15356130]

137. Fukumori T, Takenaka Y, Yoshii T, Kim HC, Hogan V, Inohara H, Kagawa S, Raz A. CD29 and CD7 mediate galectin-3-induced type II T-cell apoptosis. Cancer Res 2003;63:8302-8311. [PubMed: 14678989]

138. Zhu C, Anderson AC, Schubart A, Xiong H, Imitola J, Khoury SJ, Zheng XX, Strom TB, Kuchroo VK. The Tim-3 ligand galectin-9 negatively regulates T helper type-1 immunity. Nat Immunol 2005;6:1245-1252. [PubMed: 16286920]

139. Demetriou M, Granovsky M, Quaggin S, Dennis JW. Negative regulation of T-cell activation and autoimmunity by Mgat5 N-glycosylation. Nature 2001;409:733-779. [PubMed: 11217864]

140. Guermonprez P, Valladeau J, Zitvogel L, Thery C, Amigorena S. Antigen presentation and T-cell stimulation by dendritic cells. Annu Rev Immunol 2002;20:621-667. [PubMed: 11861614]

141. Shigematsu H, Reizis B, Iwasaki H, Mizuno S, Hu D, Traver D, Leder P, Sakaguchi N, Akashi K. Plasmacytoid dendritic cells activate lymphoid-specific genetic programs irrespective of their cellular origin. Immunity 2004;21:43-53. [PubMed: 15345219]

142. Shortman K, Liu YJ. Mouse and human dendritic cell subtypes. Nat Rev Immunol 2002;2:151-161. [PubMed: 11913066]

143. Banchereau J, Briere F, Caux C, Davoust J, Lebecque S, Liu YJ, Pulendran B, Palucka KA. Immunobiology of dendritic cells. Annu Rev Immunol 2000;18:767-812. [PubMed: 10837075]

144. Lanzavecchia A, Sallusto F. Regulation of T cell immunity by dendritic cells. Cell 2001;106:263266. [PubMed: 11509174]

145. Gabrilovich DI, Ishida T, Nadaf S, Ohm J, Carbone DP. Antibodies to vascular endothelial growth factor enhance the efficacy of cancer immunotherapy by improving endogenous dendritic cell function. Clin Cancer Res 1999;5:2963-2970. [PubMed: 10537366]

146. Ishida T, Oyama T, Carbone D, Gabrilovich DI. Defective function of Langerhans cells in tumorbearing animals is the result of defective maturation from hematopoietic progenitors. J Immunol 1998;161:4842-4851. [PubMed: 9794417]

147. Almand B, Resser J, Lindman B, Nadaf S, Clark J, Kwon E, Carbone D, Gabrilovich D. Clinical significance of defective dendritic cell differentiation in cancer. Clin Cancer Res 2000;6:17551766. [PubMed: 10815894]

148. Hoffmann TK, Muller-Berghaus J, Ferris RL, Johnson JT, Storkus WJ, Whiteside TL. Alterations in the frequency of dendritic cell subsets in the peripheral circulation of patients with squamous cell carcinomas of the head and neck. Clin Cancer Res 2002;8:1787-1793. [PubMed: 12060618] 
149. Pinzon-Charry A, Ho CS, Laherty R, Maxwell T, Walker D, Gardiner RA, O'Connor L, Pyke C, Schmidt C, Furnival C, Lopez JA. A population of HLA-DR+ immature cells accumulates in the blood dendritic cell compartment of patients with different types of cancer. Neoplasia 2005;7:11121122. [PubMed: 16354594]

150. Troy AJ, Summers KL, Davidson PJ, Atkinson CH, Hart DN. Minimal recruitment and activation of dendritic cells within renal cell carcinoma. Clin Cancer Res 1998;4:585-593. [PubMed: 9533525]

151. Enk AH, Jonuleit H, Saloga J, Knop J. Dendritic cells as mediators of tumor-induced tolerance in metastatic melanoma. Int J Cancer 1997;73:309-316. [PubMed: 9359474]

152. Nestle FO, Burg G, Fah J, Wrone-Smith T, Nickoloff BJ. Human sunlight-induced basal-cellcarcinoma-associated dendritic cells are deficient in T cell co-stimulatory molecules and are impaired as antigen-presenting cells. Am J Pathol 1997;150:641-651. [PubMed: 9033277]

153. Chaux P, Favre N, Martin M, Martin F. Tumor-infiltrating dendritic cells are defective in their antigen-presenting function and inducible B7 expression in rats. Int J Cancer 1997;72:619-624. [PubMed: 9259401]

154. Gabrilovich DI, Corak J, Ciernik IF, Kavanaugh D, Carbone DP. Decreased antigen presentation by dendritic cells in patients with breast cancer. Clin Cancer Res 1997;3:483-490. [PubMed: 9815709]

155. Bonifaz L, Bonnyay D, Mahnke K, Rivera M, Nussenzweig MC, Steinman RM. Efficient targeting of protein antigen to the dendritic cell receptor DEC-205 in the steady state leads to antigen presentation on major histocompatibility complex class I products and peripheral CD8+ T cell tolerance. J Exp Med 2002;196:1627-1638. [PubMed: 12486105]

156. Colonna M, Trinchieri G, Liu YJ. Plasmacytoid dendritic cells in immunity. Nat Immunol 2004;5:1219-1226. [PubMed: 15549123]

157. Zou W, Machelon V, Coulomb-L'Hermin A, Borvak J, Nome F, Isaeva T, Wei S, Krzysiek R, Durand-Gasselin I, Gordon A, Pustilnik T, Curiel DT, Galanaud P, Capron F, Emilie D, Curiel TJ. Stromal-derived factor-1 in human tumors recruits and alters the function of plasmacytoid precursor dendritic cells. Nat Med 2001;7:1339-1346. [PubMed: 11726975]

158. Hartmann E, Wollenberg B, Rothenfusser S, Wagner M, Wellisch D, Mack B, Giese T, Gires O, Endres S, Hartmann G. Identification and functional analysis of tumor-infiltrating plasmacytoid dendritic cells in head and neck cancer. Cancer Res 2003;63:6478-6487. [PubMed: 14559840]

159. Vermi W, Bonecchi R, Facchetti F, Bianchi D, Sozzani S, Festa S, Berenzi A, Cella M, Colonna M. Recruitment of immature plasmacytoid dendritic cells (plasmacytoid monocytes) and myeloid dendritic cells in primary cutaneous melanomas. J Pathol 2003;200:255-268. [PubMed: 12754747]

160. Munn DH, Sharma MD, Hou D, Baban B, Lee JR, Antonia SJ, Messina JL, Chandler P, Koni PA, Mellor AL. Expression of indoleamine 2,3-dioxygenase by plasmacytoid dendritic cells in tumordraining lymph nodes. J Clin Invest 2004;114:280-290. [PubMed: 15254595]

161. Mellor AL, Baban B, Chandler P, Marshall B, Jhaver K, Hansen A, Koni PA, Iwashima M, Munn DH. Cutting edge: induced indoleamine 2,3 dioxygenase expression in dendritic cell subsets suppresses T cell clonal expansion. J Immunol 2003;171:1652-1655. [PubMed: 12902462]

162. Mellor AL, Chandler P, Baban B, Hansen AM, Marshall B, Pihkala J, Waldmann H, Cobbold S, Adams E, Munn DH. Specific subsets of murine dendritic cells acquire potent T cell regulatory functions following CTLA4-mediated induction of indoleamine 2,3 dioxygenase. Int Immunol 2004;16:1391-1401. [PubMed: 15351783]

153. Fallarino F, Grohmann U, Hwang KW, Orabona C, Vacca C, Bianchi R, Belladonna ML, Fioretti MC, Alegre ML, Puccetti P. Modulation of tryptophan catabolism by regulatory T cells. Nat Immunol 2003;4:1206-1212. [PubMed: 14578884]

164. Zhang M, Tang H, Guo Z, An H, Zhu X, Song W, Guo J, Huang X, Chen T, Wang J, Cao X. Splenic stroma drives mature dendritic cells to differentiate into regulatory dendritic cells. Nat Immunol 2004;5:1124-1133. [PubMed: 15475957]

165. Steinbrink K, Wolfl M, Jonuleit H, Knop J, Enk AH. Induction of tolerance by IL-10-treated dendritic cells. J Immunol 1997;159:4772-4780. [PubMed: 9366401] 
166. Penna G, Adorini L. 1,25-dihydroxyvitamin D3 inhibits differentiation, maturation, activation, and survival of dendritic cells leading to impaired alloreactive T cell activation. J Immunol 2000;164:2405-2411. [PubMed: 10679076]

167. Wakkach A, Fournier N, Brun V, Breittmayer JP, Cottrez F, Groux H. Characterization of dendritic cells that induce tolerance and T regulatory 1 cell differentiation in vivo. Immunity 2003;18:605617. [PubMed: 12753738]

168. Kusmartsev S, Gabrilovich DI. Immature myeloid cells and cancer-associated immune suppression. Cancer Immunol Immunoth 2002;51:293-298.

169. Kusmartsev S, Gabrilovich DI. Inhibition of myeloid cell differentiation in cancer: The role of reactive oxygen species. J Leukoc Biol 2003;74:186-196. [PubMed: 12885935]

170. Nefedova Y, Huang M, Kusmartsev S, Bhattacharya R, Cheng P, Salup R, Jove R, Gabrilovich D. Hyperactivation of STAT3 is involved in abnormal differentiation of dendritic cells in cancer. J Immunol 2004;172:464-474. [PubMed: 14688356]

171. Terabe M, Matsui S, Park JM, Mamura M, Noben-Trauth N, Donaldson DD, Chen W, Wahl SM, Ledbetter S, Pratt B, Letterio JJ, Paul WE, Berzofsky JA. Transforming growth factor-beta production and myeloid cells are an effector mechanism through which CD1d-restricted T cells block cytotoxic T lymphocyte-mediated tumor immunosurveillance: abrogation prevents tumor recurrence. J Exp Med 2003;198:1741-1752. [PubMed: 14657224]

172. Bronte V, Wang M, Overwijk W, Surman D, Pericle F, Rosenberg SA, Restifo NP. Apoptotic death of CD8+ T lymphocytes after immunization: induction of a suppressive population of Mac-1+/Gr-1 + cells. J Immunol 1998;161:5313-5320. [PubMed: 9820504]

173. Gabrilovich DI, Velders M, Sotomayor E, Kast WM. Mechanism of immune dysfunction in cancer mediated by immature Gr-1+ myeloid cells. J Immunol 2001;166:5398-5406. [PubMed: 11313376]

174. Li Q, Pan PY, Gu P, Xu D, Chen SH. Role of immature myeloid Gr-1+ cells in the development of antitumor immunity. Cancer Res 2004;64:1130-1139. [PubMed: 14871848]

175. Kusmartsev S, Nefedova Y, Yoder D, Gabrilovich DI. Antigen-specific inhibition of CD8+ T cell response by immature myeloid cells in cancer is mediated by reactive oxygen species. $\mathrm{J}$ Immunol 2004;172:989-999. [PubMed: 14707072]

176. Kusmartsev S, Nagaraj S, Gabrilovich DI. Tumor-associated CD8+ T cell tolerance induced by bone marrow-derived immature myeloid cells. J Immunol 2005;175:4583-4592. [PubMed: 16177103]

177. Huang B, Pan PY, Li Q, Sato AI, Levy DE, Bromberg J, Divino CM, Chen SH. Gr-1+CD115+ immature myeloid suppressor cells mediate the development of tumor-induced T regulatory cells and T-cell anergy in tumor-bearing host. Cancer Res 2006;66:1123-1131. [PubMed: 16424049]

178. Bronte V, Serafini P, De Santo C, Marigo I, Tosello V, Mazzoni A, Segal DM, Staib C, Lowel M, Sutter G, Colombo MP, Zanovello P. IL-4-induced arginase 1 suppresses alloreactive T cells in tumor-bearing mice. J Immunol 2003;170:270-278. [PubMed: 12496409]

179. Kusmartsev S, Gabrilovich D. STAT1 signaling regulates tumor-associated macrophage-mediated T cell deletion. J Immunol 2005;174:4880-4891. [PubMed: 15814715]

180. Almand B, Clark JI, Nikitina E, English NR, Knight SC, Carbone DP, Gabrilovich DI. Increased production of immature myeloid cells in cancer patients. A mechanism of immunosuppression in cancer. J Immunol 2001;166:678-689. [PubMed: 11123353]

181. Danna EA, Sinha P, Gilbert M, Clements VK, Pulaski BA, Ostrand-Rosenberg S. Surgical removal of primary tumor reverses tumor-induced immunosuppression despite the presence of metastatic disease. Cancer Res 2004;64:2205-2211. [PubMed: 15026364]

182. Schmielau J, Finn OJ. Activated granulocytes and granulocyte-derived hydrogen peroxide are the underlying mechanism of suppression of T-cell function in advanced cancer patients. Cancer Res 2001;61:4756-4760. [PubMed: 11406548]

183. O`Neill DW, Adams S, Bhardwaj N. Manipulating dendritic cell biology for the active immunotherapy of cancer. Blood 2004;104:2235-2246. [PubMed: 15231572]

184. Dudley ME, Rosenberg SA. Adoptive-cell-transfer for the treatment of patients with cancer. Nat Rev Cancer 2003;3:666-675. [PubMed: 12951585]

185. Finn OJ. Cancer vaccines: between the idea and the reality. Nat Rev Immunol 3:630-641. [PubMed: 12974478] 
186. Pure E, Allison JP, Schreiber RD. Breaking down the barriers to cancer immunotherapy. Nat Immunol 2005;6:1207-1210. [PubMed: 16369561] 


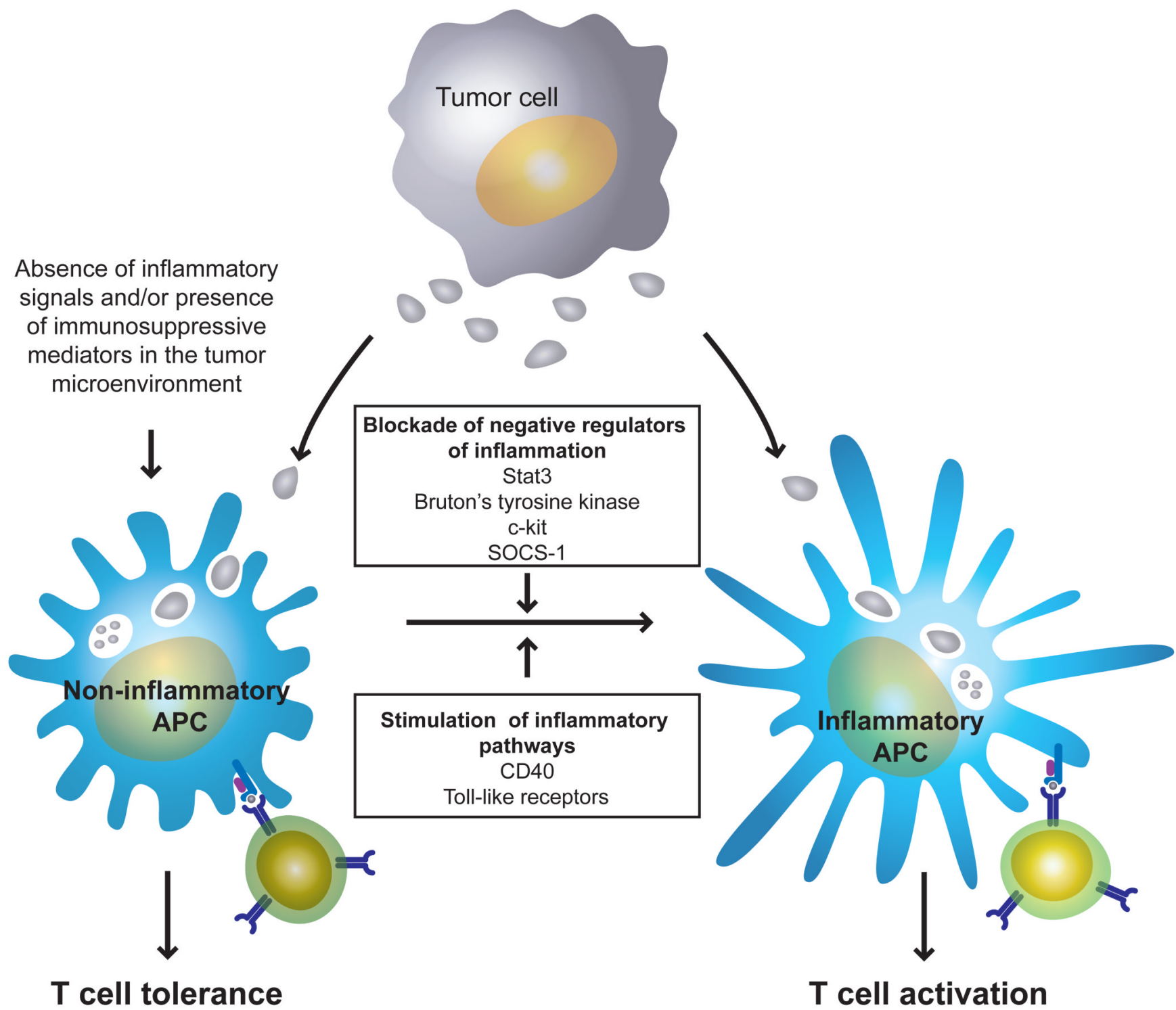

Figure 1. Conversion of tumor-induced T-cell tolerance to T-cell activation In the immune response to tumors, BM-derived APCs capture tumor antigens at the tumor site and then migrate to the secondary lymphoid organs for presentation of antigenic peptides to tumor-specific T-cells. In the absence of inflammation and/or or in the presence of a "hostile" environment characterized by immunosuppressive factors at the tumor site, this process invariable leads to the induction of T-cell tolerance. However, generation of inflammatory APCs by either stimulating inflammatory pathways or by blocking negative regulators of inflammation in these cells can convert an APC/T-cell encounter from a tolerogenic event into a priming event in the tumor-bearing host. 


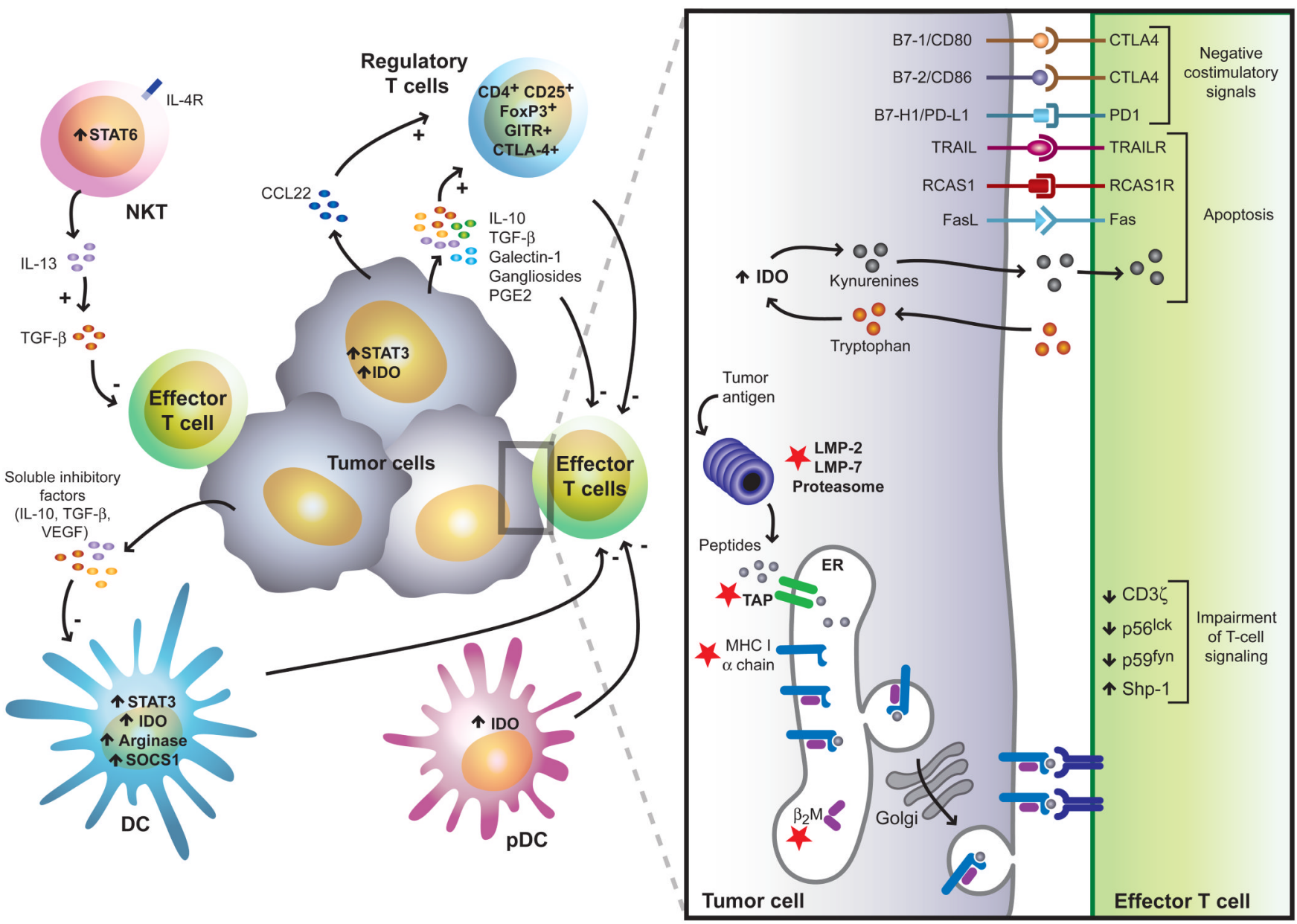

Figure 2. Immunosuppressive strategies and immunological checkpoints exploited by tumors to evade immune responses

Tumors employ a plethora of immunosuppressive mechanisms, which may act in concert to counteract effective immune responses. These include defects in TCR proximal signals, tumorinduced impairment of the antigen presentation and processing machinery (red stars), activation of negative costimulatory signals in the tumor microenvironment (CTLA-4/B7, PD-1/PD-L1), elaboration of immunosuppressive factors (IL-10, TGF- $\beta$, galectin-1, gangliosides, $\mathrm{PGE}_{2}$ ), activation of proapoptotic pathways (FasL, TRAIL, IDO, RCAS1), inhibition of NK-cell mediated cytotoxicity (e.g release of soluble MICA) and inhibition of DC differentiation and maturation (STAT3, VEGF, IL-10, SOCS1, arginase). In addition, different regulatory cell populations contribute to this immunosuppressive network including $\mathrm{CD}^{+} \mathrm{CD} 25^{+}$regulatory T-cells, inducible Tr1 cells, IL-13-producing NKT cells and distinct subsets of immature and mature myeloid and plasmacytoid DCs. 
Regulatory DCs are generated in the presence of tumorderived factors. They are not a separate subset of DCs but are functionally distinct from iDC. They can induce T-cell
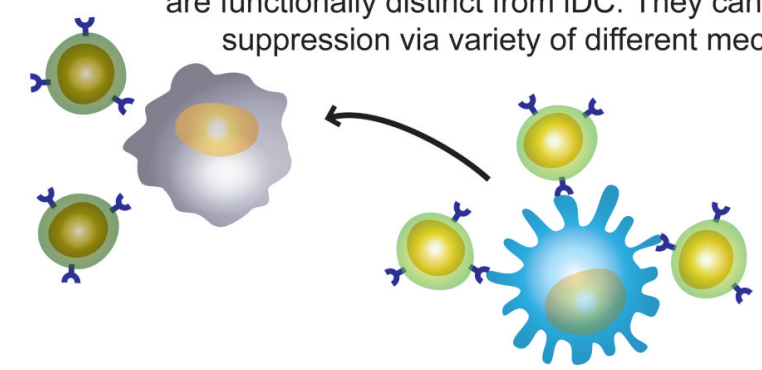
anisms.
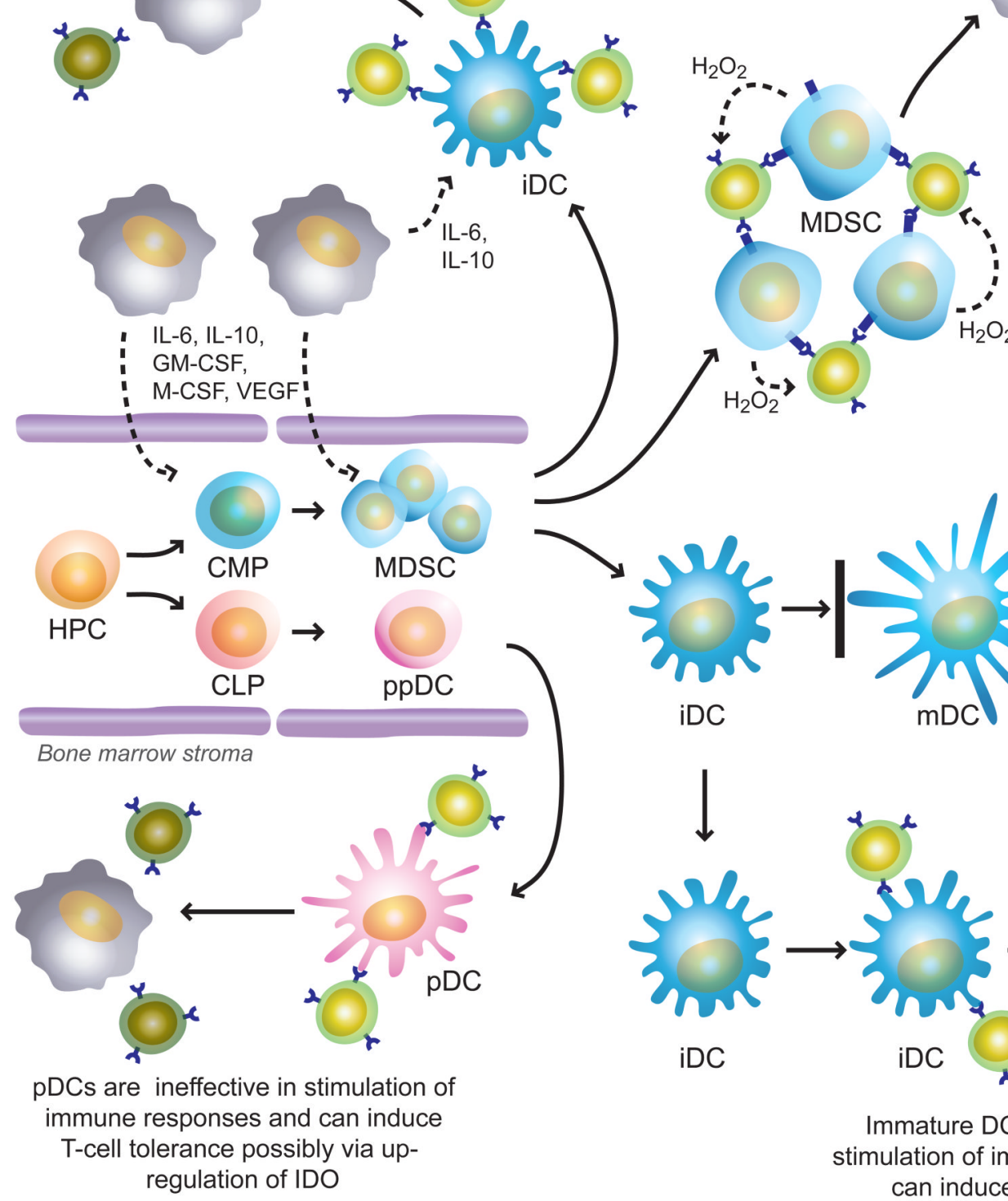
specific T cells via direct cell-cell contact that involves reactive oxygen species, primarily $\mathrm{H}_{2} \mathrm{O}_{2}$

Figure 3. Differentiation of DCs and their contribution to the immunosuppressive network in cancer

DCs are differentiated in bone marrow from hematopoietic progenitor cells (HPC) alongside two major pathways. One is a myeloid-cell pathway that include common myeloid precursors (CMP) and immature myeloid cells (MDSC). The latter cells represent the population of immediate precursors of myeloid cells (granulocytes, macrophages, and DCs). In the periphery MDSC differentiate into immature DCs (iDC), which after encounter of different stimuli become activated or mature DCs (mDCs). The other pathway of DC differentiation includes common lymphoid precursors (CLP) and precursors of plasmacytoid DCs (ppDCs). These cells in the periphery become plasmacytoid DCs (pDC). Through a number of tumor-derived factors, 
tumors alter DC differentiation that results in increased production of $\mathrm{pDC}$, accumulation of iDC, and immunosuppressive regulatory DCs and myeloid-derived suppressor cells (MDSC). All these populations of cells are able to suppress antigen-specific immune response in cancer via different mechanisms. 